\title{
Spatial and Behavioral Correlates of Striatal Neurons in Rats Performing a Self-Initiated Navigation Task
}

\author{
Sidney I. Wiener \\ CNRS-Collège de France Laboratoire de Physiologie de la Perception et de l'Action, 75270 Paris Cedex 06, France
}

To investigate the spatial and behavioral correlates of striatal neurons during displacement movements, the rostromedial dorsal striata (AP 1.0-2.2, ML 1.5-2.0) of five rats were surgically implanted with advanceable bundles of fine wire electrodes. After recovery, the rats were deprived of water and trained in a square-walled open field in a dark room. The behavioral task required alternating visits to water reservoirs in the center and in the four corners. A certain corner contained the first reward for each trial; after this reward, a cue card appeared in this corner for the rest of the trial.

The firing rates of striatal units were compared as the rat moved between the center and the four corners of the arena. Analyses were made of $\mathbf{3 0}$ units. Eight of these had firing rates that significantly increased or decreased by $62-480 \%$ while the rat was in one or more quadrants of the arena. Six of these manifested such firing rate changes only as the rat performed certain behavioral sequences in the quadrant. Three other units fired as the rat's head was in a certain orientation relative to the arena walls, in all parts of the arena.

To determine the principal controlling cues and hence the frame of reference of spatial selectivity of these units, the arena, while the rat was still inside, was rotated in total darkness. The first water reward was then presented at the same position relative to the outside room as before the rotation. The cue card was then illuminated in this corner as a visual cue for the extra-arena reference frame. All 11 neurons demonstrated spatial selectivity that rotated with the arena; thus, this activity was in the frame of reference of the arena and was not controlled by the visual cue.

Six other units fired at rates up to six times their resting discharge or stopped firing completely in synchrony with

\footnotetext{
Received July 8, 1992; revised Mar. 1, 1993; acceptcd Mar. 9, 1993.

Thanks to A. Berthoz for support in all aspects of this work, M. Chat for histology, S. Lemarchand for animal care, M. Ehrette for mechanical technical assistance, B. Delord for help with software development, C. Poirier and A. Quillivic for assistance with figures, B. Caceres for assistance with movement analyses, and to many colleagues for important comments and suggestions including $A$ Berthoz, H. Diecke, A. Etienne, B. Hess, F. Lestienne, J. O'Keefe, M. Potcgal, H Eichenbaum, F. Miles of A-M Systems, Inc., and the staff of Cambridge Electronic Design, Ltd. The tracking system was conceived and constructed in collaboration with M. Julian based on an original design of M. Kuperstein. Grant support was generously provided by the Fogarty Institute/INSERM Senior Fellowship, CNRS Poste Rouge, NATO Senior Fellowship, Fondation Fyssen, Fondation pour la Recherche Médicale, the CEC/ESPRIT/BRA 3149 MIJCOM, and the Human Frontiers program.

Correspondence should be addressed to Sidney I. Wiener, CNRS-Collège de France UMR-C 9950, 15 rue de l'Ecole de Médecine, 75270 Paris Cedex 06, France.

Copyright (C) 1993 Society for Neuroscience $0270-6474 / 93 / 133802-16 \$ 05.00 / 0$
}

initiation or execution of displacement movements, and two of these were also location selective. Four other units were silent as the rat performed the task, but fired tonically following arena rotations or other interruptions of the session, independent of the rat's location or movements. Nine analyzed units had very low firing rates ( $<1$ impulse/sec) and showed no discernible changes in activity as the rat performed the task.

These patterns of unit activity indicate that fundamental informational components required for navigation are coded in the striatum. These include the rat's location, heading direction, and the timing of the initiation and execution of displacement movements.

[Key words: caudate nucleus, corpus striatum, directional firing, spatial firing, locomotion, reference frames]

Patients with basal ganglia disorders commonly present abnormal movements during gaze shifts, manipulation, reaching, locomotion, and posture maintenance. Human and animal studies show that deficits in cognitive processing can also occur (for reviews, see Teuber, 1976; Masuda and Iwasaki, 1984; Dubois et al., 1991). For example, Parkinson's disease patients have diminished "mental flexibility" (Bowen et al., 1976), while Huntington's patients perform poorly in a task requiring spatial memory in an egocentric (i.e., self-centered) reference frame (Potegal, 1971). Rats with striatal lesions perform more poorly than controls in some navigation tasks (e.g., Potegal, 1969; Masuda and Iwasaki, 1984; Whishaw et al., 1987; Cook and Kesner, 1988; Packard et al., 1989).

While no neurophysiological recordings have, until now, been made from the striatum of animals performing navigation tasks, striatal neuronal activity is clearly correlated with more than the mechanical aspects of control of eye or head movements. In traincd monkcys, striatal ncurons arc responsive to the appearance of sensory stimuli that are related to task movements (Hikosaka et al., 1989b) and to the initiation of task-related movements (Schultz and Romo, 1988; Hikosaka et al., 1989a; Alexander and Crutcher, 1990b; Kimura, 1990), as well as preparation for movement (Alexander and Crutcher, 1990a) and anticipation of reward (Hikosaka et al., 1989c; Apicella et al., 1991). The unit activity is not striclly correlated with the anatomical and biomechanical requirements of movements and may be tuned according to the amplitude or direction of the actual displacement of the forelimb (Crutcher and DeLong, 1984; Mitchell et al., 1987) or the controlled cursor (Alexander and Crutcher, 1990b) in space. It is not clear whether these neurons are tuned to spatial positions determined relative to the monkey or, alternatively, to some external referent(s). A goal of the present study was to test if striatal unit responses also occur for body 
displacement movements and to determine the nature of their spatial referents.

The spatial correlates of unit activity during displacement movements have most frequently been studied in the hippocampal and parahippocampal regions of freely moving rats. Pyramidal cells of areas $\mathrm{CA} 1$ and $\mathrm{CA} 3$ of the hippocampus fire [5-20 impulses (imp)/sec] preferentially when the rat occupies small locations in its environment called "firing fields" (Muller et al., 1987a) or "place fields" (O'Keefe and Conway, 1978) and, in some cases, while the rat is facing particular directions in this field (McNaughton et al., 1983; Wiener et al., 1989). Postsubiculum cells fire at up to $80 \mathrm{imp} / \mathrm{sec}$ when the rat faces a certain direction, regardless of the rat's position in an open field (Taube et al., 1990a). These place and heading-direction correlates are controlled by cues on the periphery of the maze, even when the cues are not visible (Muller et al., 1987b; Quirk et al., 1990; Speakman and O'Keefe, 1990; Taube et al., 1990b) and thus are allocentrically referred. Since the hippocampal and parahippocampal regions send projections to the striatum (Kelly and Domesick, 1982; Swanson and Köhler, 1986; McGeorge and Faull, 1989), it seemed likely that striatal neuronal activity would also be corrclated with displacement movements and the position of the rat, although lesion studies indicate that the reference frames of striatal units would be different from those of hippocampus (e.g., Packard et al., 1989).

To move accurately in space, one must know the starting point, the terminal point, and the route to follow. These data must be defined in relation to a point of reference, which can be either one's previous position or a distant landmark (e.g., see Leonard and McNaughton, 1990). An entirely allocentric strategy to compute routes can involve spatial maps, where the fundamental reference is an overview of all of the topographic relations between landmarks; continuous updating of one's position on this map is based upon one's perceived position relative to these landmarks. Conversely, a navigation algorithm could be based upon a single reference point, such as a nest, and one's position could be calculated by integrating information about one's translational and rotational displacements relative to that point. Since such self-movement (or "idiothetic"; Mittelstaedt and Mittelstaedt, 1973) information comes from the vestibular, proprioceptive, and kinesthetic inputs, this computation would originate from an egocentric, self-centered frame of reference.

To compare the roles of egocentric and allocentric reference frames, a navigation task was designed based on the radial arm maze (Olton and Samuelson, 1976; Wiener et al., 1989) in requiring alternating, nonrepeated visits to each extremity and the center of the maze. Striatal neuronal activity was studied for spatial and behavioral correlations. Following rotations of the rat and arena in the dark, units were studied to see if their spatial selectivity rotated with the intra-arena reference frame or if this selectivity was determined by the visual cue and the extra-arena reference frame.

\section{Materials and Methods}

\section{Electrode implantation and histology}

Five male Long-Evans hooded rats weighing between 330 and $400 \mathrm{gm}$ were anesthetized with xylazine and pentobarbital. Then a headstage bearing two independent bundles of microelectrodes was implanted into the medial aspect of the rostral pole of the caudate nucleus (AP 1.22.4, ML 1.2-2.4 relative to bregma) and in the hippocampus (S. I. Wiener, R. Garcia, and A. Berthoz, unpublished observations) using conventional surgical techniques. The electrodes were bundles of eight $25 \mu \mathrm{m}$, Formvar-insulated nichrome wires inserted in stainless steel cannulas $(0.39 \mathrm{~mm}$ external diameter $)$ and mounted on microminiature connectors. Two such independently advanceable assemblies were mounted on a single headstage. A full turn of the two screws connecting the electrode to its mounting advanced the electrode by $300 \mu \mathrm{m}$ (maximum range, $4 \mathrm{~mm}$ ). Following electrode advances, recordings were not attempted for at least $3 \mathrm{hr}$. Only a single descent was made with each cannula in each rat. Due to the high density of myelinated fibers in this region of the striatum, the use of an electrode configuration capable of multiple penetrations and continuous recording following electrode advances (e.g., Gardiner and Kitai, 1992) is recommended for future studies.

Two days after recovery, water consumption was restricted to maintain body weight at $80 \%$ of presurgical levels and behavioral training began. At the end of the experiments, the rats were rehydrated, and then administered an overdose of pentobarbital. Intracardial perfusion with saline was followed by formalin. Histological sections were stained with cresyl violet. Recording sites were reconstructed by detecting the deepest position of the guide tube, adding $500 \mu \mathrm{m}$ for the protrusion of the electrode wires and subtracting the distance that the electrode had been advanced. No evidence of striatal compression was apparent. Identification of the striatum was reconfirmed with phase-contrast optics by the presence of the characteristic myelinated fiber bundles ("striata"; Brodal, 1981, p 211).

\section{Behavioral and physiological recordings}

Two lamps were mounted at a separation of $9 \mathrm{~cm}$ onto the preamplifier plug assembly, which was attached to the headstage during recording sessions. The lamp in the rostral position was fitted with a red filter $(680 \mathrm{~nm}$ peak, $600 \mathrm{~nm}$ cutoff) while the caudal lamp had a blue filter (480 $\mathrm{nm}$ peak, $80 \mathrm{~nm}$ band width). The two lamps' positions were detected with a CCD color TV camera mounted above the arena and a custom-built real-time tracking system with a sampling rate of $20 \mathrm{~Hz}$. The tracking system decoded the red and blue video signals into analog signals proportional to the $\mathrm{x}$ - and $\mathrm{y}$-components of the two lamps' positions in the horizontal plane. The maximum error of resolution of the $(2 \times 3 \mathrm{~mm})$ headstage-mounted lamps is estimated from the image on the TV monitor as about $5 \mathrm{~mm}$ due to "blooming" (an enlarging distortion of the video image) and an error due to the tracking system, wherein it computed the position of an upper left edge rather than the center of each lamp. Thus, the heading direction measurcments are subject to errors of up to $12^{\circ}$.

After $1 \times$ amplification with field effect transistors (stated leakage current less than femtoampere), recordings were differentially amplified $(10,000 \times)$, filtered $(300 \mathrm{~Hz}$ to $10 \mathrm{kHz}$, notch at $50 \mathrm{~Hz})$, and recorded on eight-channel wide-band FM tape. Simultaneously, all of the behavioral data were multiplexed into a single channel and recorded onto this same tape. Due to the fast tape speeds required to record the multiplexed signal and the scarcity of this tape, not all of the cells encountered were actually recorded and analyzed.

After the recording session, data were played back from the eighttrack tape, demultiplexed, and acquired onto a personal computer. A multichannel (amplitude and duration) window discriminator determined spike occurrences and also further decoded the multiplexed photobeam signal. Amplitude windows wcre set at less than or equal to $10 \%$ of the maximum of the spike waveform. The waveform and trigger signal of the unit with the weakest signal-to-noise ratio (minimum of $3: 1$, but usually much higher) were monitored continuously on a delayed trigger oscilloscope. Artifactual triggers were noted and excluded from the analyses of all channels. In several recording sessions of only one unit with a high $(>10: 1)$ signal-to-noise ratio, data were acquired directly onto the computer without using the tape recorder. In these cases, artifactual triggers were rejected on line.

\section{Behavioral task and experimental arena}

The arena was a coverless $60 \mathrm{~cm}$ cubic box (Fig. 1) that was painted matte black. There was a water reservoir in the center of the floor and also at each of the four corners at $4 \mathrm{~cm}$ from the walls. Reflective tapc on each reservoir was targeted by a dedicated infrared photoemitter/ photodetector. As the rat successively blocked the photobeams while searching for water, the computer triggered the delivery of the water rewards. The photobeam signals were recorded for later analyses.

In order to provide a dominant visual cue marking the extra-arena reference frame, a double light-emitting diode (LED) in a green casing was mounted in each corner at a height of $26 \mathrm{~cm}$ above the arena floor. 
Each IED was directed toward a white paper rectangle $(15 \times 7.5 \mathrm{~cm})$ mounted $18 \mathrm{~cm}$ above the floor and attached horizontally along the junction of the walls. The illuminated paper, or "cue card," subtended a visual angle ranging from $11^{\circ}$ to $22^{\circ}$ horizontally and $13^{\circ}$ to $16^{\circ}$ vertically depending upon the position of the rat in the arena.

The experiments took place in a completely darkened room that was acoustically isolated except for the doorway, which was covered by two layers of felt curtains. To human observers, the doorway provided a focalized source of low-intensity auditory cues. Although the solenoid valves were positioned outside the experimental chamber, their lowvolume click was audible within. During the recording sessions, the instrumentation, the experimenter, and other rats were in an adjacent room where the lights were also turned off. Each day, all experimental rats, in their separate cages with clear plastic walls, were brought to the room outside the experimental chamber and remained there during recording sessions. Prior to recordings, each rat had a minimum of six sessions in the arena including at least two sessions with rotations.

The arcna was mounted on a swivel and could be rotated from outside the experimental chamber by a manually driven pulley system (see Fig. 1). A potentiometer measured this angle.

\section{Experimental design}

In the bchavioral paradigm, the rat was presented with two distinct types of spatial cues. Intra-arena cues rotated with the rat and extraarena cues remained stationary with respect to the reference frame of the earth. In the intra-arena reference frame, the corners will be referred to as "A," "B," "C," and "D." In the extra-arena reference frame, the positions of the arena corners will be referred to in geographic terms ("southeast," etc.) to emphasize stationarity (actual compass points were not used).

The rat repeated a series of visits to the water reservoirs. All movements were freely initiated by the rat without trigger cues except for the extinction of the cue card in step D. The sequence was as follows (see Fig. 2):

1. No cue cards were illuminated. A water reward could only be found at the "southeast" reservoir. The rat could have found this first corncr with navigation and memory strategies or, cspecially while learning the task, by trial and error.

2. The next water reward was delivered at the central reservoir. Then the cue card in the southeast corner was illuminated until the end of the trial.

3. The rat was then rewarded for visits to each of the remaining corner reservoirs in alternation with visits to the center. The sequential order of these comer visits was not controlled. Repeated visits to individual corners were not rewarded.

4. After the fourth corner reward, the rat again was rewarded at the central reservoir. The cue card light was turned off and the cycle was restarted at step $A$ with a visit to the reservoir in the southeast corner.

5 . At 2-5 min intervals, all lights in the arena were turned off, including those on the rat's headstage.

6 . Then the arena, with the rat inside, was rotated by a pseudorandomly selected angle of $90^{\circ}, 180^{\circ}$, or $270^{\circ}$, either clockwise or counterclockwise. The arena was rotated at approximately $90 \% \sec (0.25 \mathrm{~Hz}$, within the normal range of sensitivity of the vestibular system; see, e.g., Hess et al., 1989).

7. A new trial then began as in step 1: the first reward was delivered at the corner reservoir that was then in the southeast position in the room. In Figure $2 G$, this would correspond to corner $D$. After the rat received a reward at this reservoir and returned to the center, the cue card in this same corner was illuminated for the rest of the trial, and the task sequence continued at step $\mathrm{C}$.

The behavioral task was directed entirely by a PC-AT-compatible personal computer with a commercial interface, except for step F. Normally, there was no contact between experimenter and rat during the recording session.

In order to compare neuronal firing rates as the rat performed similar behaviors, records were excluded if they involved abnormal trajectories, for example, if the rat walked directly between two corners without visiting the center. Anomalous trajectories (and unrewarded visits) were not found to occur preferentially at a particular reservoir. Measurement of the precise number of incorrect visits was not possible due to technical difficulties such as determining whether head movements at a water reservoir were head bobbing, as occurs during grooming, or whether these were repeated visits. However, for all of the rats, it is estimated that well over $70 \%$ of the reservoir visits were in the correct sequence

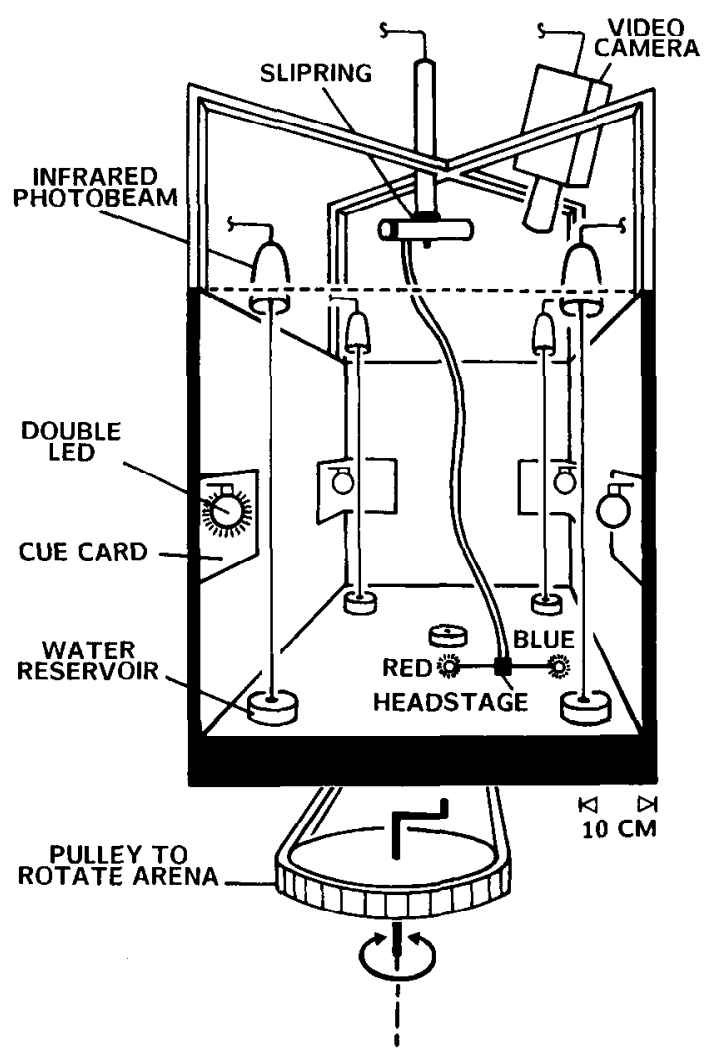

Figure 1. Schematic diagram of the experimental arena in a cutaway view from the front. Prior to the experiments, the headstage that carried the red and blue bulbs was mounted onto the electrode assembly on the rat's head. When the rat arrived at a water reservoir, a signal from the photobeam was sent to the computer, which then triggered a water reward delivery at the reservoir. The two photobeams directed at the central reservoir are not shown. The pulley system for rotating the arena was operated from a room adjacent to the one containing the arena.

and hence were rewarded. It was not possible to test for reward-related unit responses since nonrewarded visits were often rejected for analysis on the basis of trajectory criteria. The rats often visited the reservoirs in stereotyped sequences. This resulted in incorrect $(<50 \%)$ performance of the first visit following the rotations. This does not affect the interpretation of the results since these trials were often excluded on the basis of anomalous trajectory. In addition, this experiment tests the spatial correlates of the unit activity relative to the cues rather than the postrotation performance. Rewards were delivered at an average rate of about 10 per minute. Sessions lasted from 12 to $35 \mathrm{~min}$ and thus had up to 350 rewarded reservoir visits.

\section{Data analyses}

Analyses for location-selective firing. The arena floor was divided into a $16 \times 16$ array of squares with $3.3 \mathrm{~cm}$ sides. For each sampling period $(50 \mathrm{msec})$ that the blue bulb on the rat's head was detected in a square, the neuronal impulse count for that period were accumulated into a corresponding counting bin (of 256 possible bins). To calculate the average firing rate, the total count for each square over the entire session was divided by the total time that the rat occupied the square $(2 \mathrm{sec}$ minimum).

Location-selective firing plots are shown strictly for comparison with previous studies. Statistical analyses of these data were not attempted since this would pool data corresponding to a broad and widely variable range of behaviors that the rat performs at each particular location. This same critique holds for differences in sensory inputs and local reward associations as the rat occupies the different parts of the arena: spatial differences in firing rate could not be conclusively linked to any single factor such as the animal's position.

Experimental design. To control for location-specific differences in sensory cues, motor behaviors, or reward contingencies, the layout of 

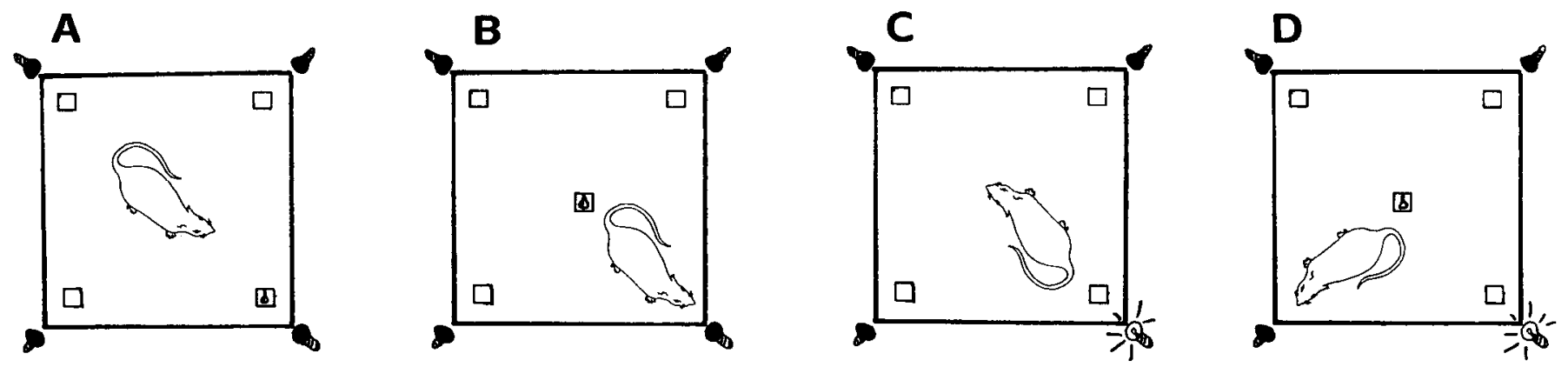

$\mathbf{E}$

EXTRA-MAZE

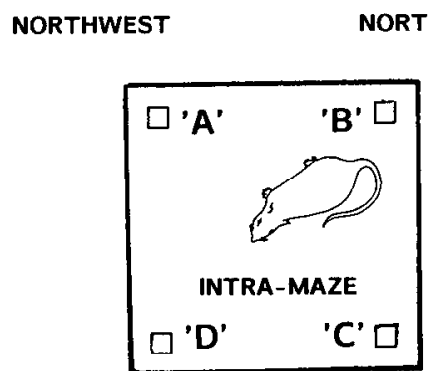

SOUTHWEST

SOUTHEAST

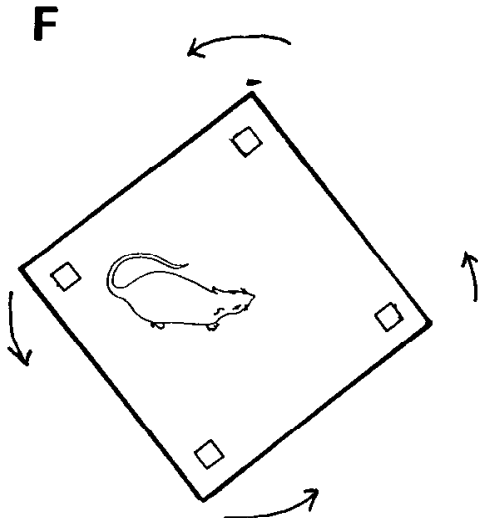

G

EXTRA-MAZE

Figure 2. This overhead view of the arena shows the sequence of events in the behavioral task. The water reservoirs are shown as small squares in the four corners and center. The square containing the water droplet is the next reservoir to be rewarded in the task sequence. The illuminated cue card is indicated by the white light bulb. $A$, The rat must first visit the southeast corner $(B)$. Then, the rat must return to the center $(C)$. The cue card in the southeast corner is illuminated. $D$, The rat is rewarded once at each of the remaining corners in alternation with center visits. After all four corners have been visited, the cue card lighting is extinguished and the trial starts again at $A$. $E$, Every 2-5 min, all lights are extinguished including those on the headstage. $F$, The arena is rotated by $90^{\circ}, 180^{\circ}$, or $270^{\circ}$ in either direction with a pseudorandom sequence. $G$, The next trial begins again at step $A$ with a visit to the reservoir now in the southeast and continues as above. The corners are identified by the lettering system of $E$ throughout the article.

the arena had a four-way axis of symmetry and the behavioral task required the same movements in each quadrant of the arena. The null hypothesis is that unit activity would not vary as the rat performs the same behavioral sequences in the different quadrants of the arena.

Synchronizations with arrivals at and departures from the water reservoirs. The photodetector signals (see Fig. 1) indicating the start and end of the rat's movements served as triggers to synchronize analyses of cell activity. In some units with activity correlated with the rat's movements, for greater clarity the synchronization point was instead selected as the instant that the rat crossed the midpoint between the reservoirs. Failures to detect the rat's headlamps are indicated by sharp triangular interruptions of the movement traces, many of which have been retouched for clarity of presentation. Curves in the rat's trajectory caused a slight temporal shift between the $\mathrm{x}$ and $\mathrm{y}$ head displacement traces (e.g., see Fig. 4). Since the trajectory curvatures had the same sense, $\mathrm{x}$-traces for corners $\mathrm{A}$ and $\mathrm{C}$ are comparable to $\mathrm{y}$-traces for corners $\mathrm{B}$ and $\mathrm{D}$ (and $\mathrm{x}$ at $\mathrm{B}$ and $\mathrm{D}$ are comparable to $\mathrm{y}$ at $\mathrm{A}$ and $\mathrm{C}$ ).

\section{Statistical tests}

The analyses focused on the $1 \mathrm{sec}$ periods prior to and following the synchronization points. These periods were subdivided into eight intervals each lasting $250 \mathrm{mscc}$. This sample interval was found to give an optimal temporal resolution while grouping similar movement patterns together across trials. Each of the $250 \mathrm{msec}$ intervals corresponds to a degree of progress as the rat moved between center and corner and thus a step in the sequence of displacement behaviors: standing still, initiating displacement, active displacement, deceleration, at rest again. The traces vary from trial to trial, reflecting differences in trajectories that are to be expected in a freely moving animal. However, in all cases reported for statistical analyses, the timing of the movements (movement onset, termination, and velocity) remained similar in the four quadrants; trials satisfying this criterion had displacements between the corner and center reservoirs in less than $2 \mathrm{sec}$. Trials following arena rotations or including grooming bouts rarely satisfied these conditions. Possible errors resulting from variations in trajectory timing are discussed below.

Since the population of data measures (i.e., firing rates in $250 \mathrm{msec}$ periods synchronized with arrivals or departures) did not appear to be normally distributed for each of the neurons tested, these measures were transformed with the

$$
x^{\prime}=\sqrt{x}+\sqrt{x+1}
$$

transform (Winer, 1971; cited by O'Keefe and Speakman, 1987, p 7). This repeated-measures experimental design helps to reduce serial correlation effects by a type of randomization: successive measures in each quadrant were separated by measures in other quadrants at variable intervals due to the task requirement that the rat alternate visits between reservoirs. While parametric statistical tests such as the standard $t, F$, and ANOVA analyses generally require a population of subjects, they may be justified for measures from a single subject only in the case of no significant autocorrelation of the measures (Kazdin, 1984, p 294). Sequential correlation analyses were performed, and in none of the reported data was a significant $(p<0.05)$ autocorrelation found. In addition, a significance level of $p<0.005$ was selected for the ANOVAs in order to reduce the risk of type I errors resulting from simultaneously performing multiple tests that could be dependent (Bonferroni procedure of Holm, 1979, as cited by Krauth, 1988, p 36).

In order to screen the data for important effects, first a $4 \times 8$ factorial analysis of variance $(4 \times 8$ ANOVA) was performed on the (transformed) firing rates corresponding to when the rat reached matched levels of progress in the trajectory between the corner and the center ("trajectory" factor) in each of the four quadrants ("quadrant" factor) over all of the trials. This analysis can also be considered in terms of a polar coordinate system with the center of the arena as the origin: the quadrant factor is angle and the trajectory factor is the distance from the center. The 
CORNER 'A'

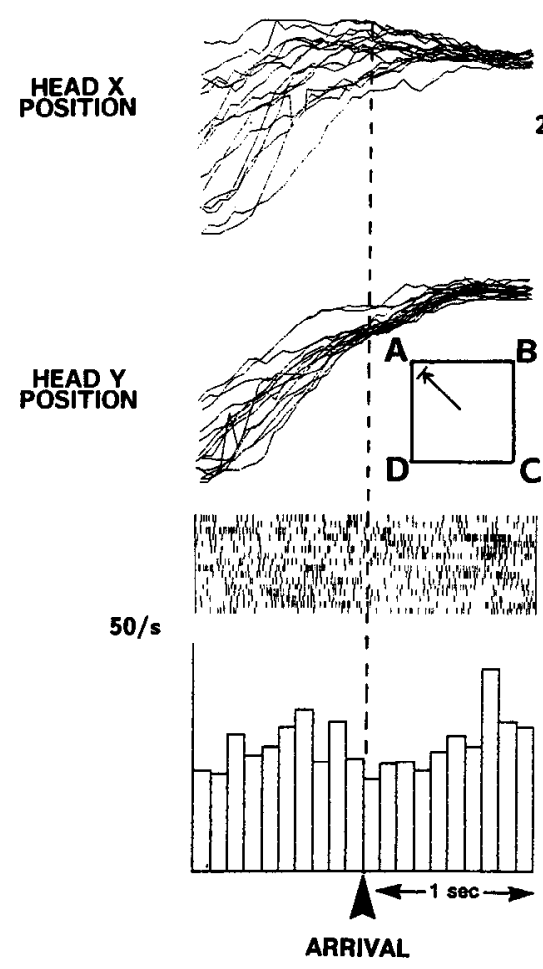

CORNER 'B'

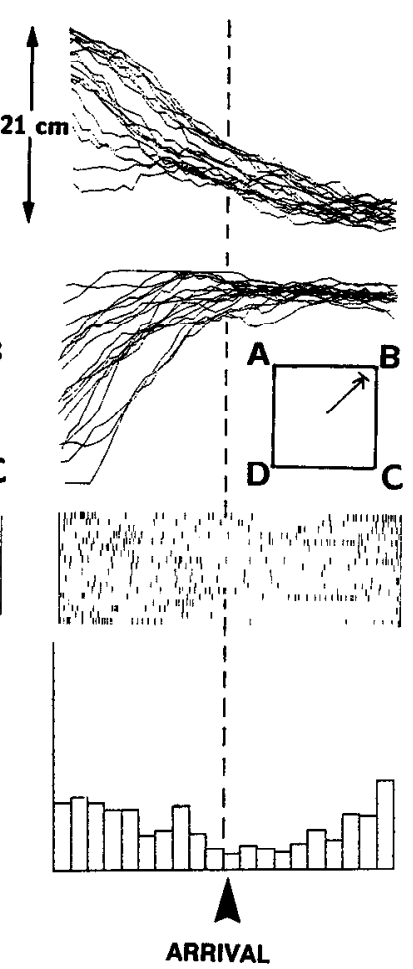

CORNER 'C'
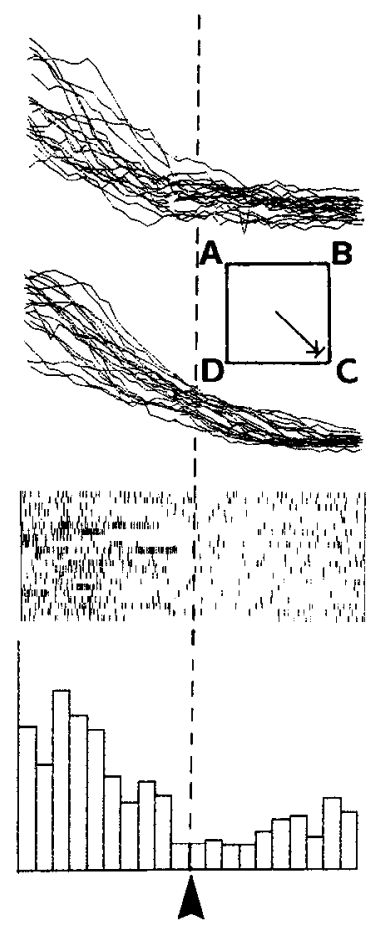

ARRIVAL
CORNER 'D'

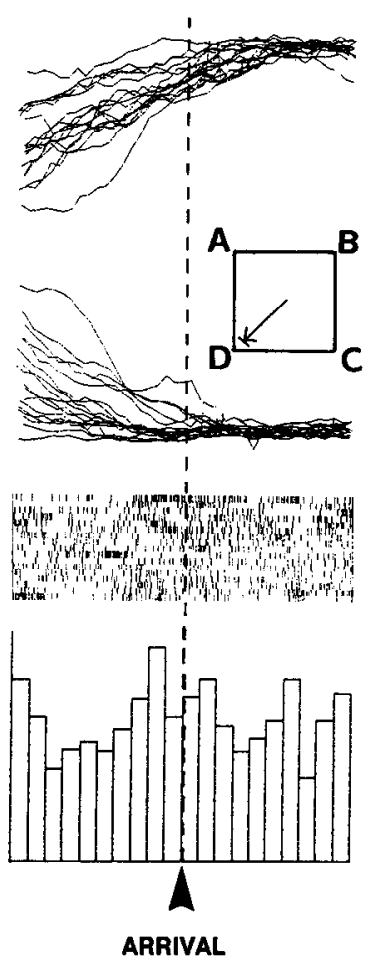

Figure 3. Head displacements and unit activity for the $1 \mathrm{sec}$ period prior to and following the rat's arrivals at the respective corner reservoirs (synchronization point is arrowhead below histograms). The upper traces show the $\mathrm{x}$ (axis between corners $A$ and $B$ ) and $\mathrm{y}$ (axis between corners $B$ and $C$ ) components of the rat's head displacement. The displacements shown are on an offset scale displaying the distance from each respective corncr to the center; this was $21 \mathrm{~cm}$ from start to finish for $\mathrm{x}$ and for $\mathrm{y}$. The inset figures are schematic representations of the trajectory as seen from an overhead view of the arena. The arrow shows the direction that the rat moved; the perpendicularbar on the arrow indicates the synchronization point. The unit activity is displayed in rasters and in histograms with bin widths of $100 \mathrm{msec}$. This unit's firing rate decreased as the rat arrived at corners $B$ and $C$. Since the synchronization point is measured as the instant that the rat first blocked the photobeam, there are some slight displacement movements that follow this. The timing of the rat's movements for all periods that are reported in statistical analyses did not appear to be fundamentally different at the four corners.

quadrant factor tested for location-selective changes in the cell's (transformed) firing rate. A significant value of $F$ for the trajectory factor indicates that the firing rate increased or decreased as the rat moved between the center and each corner. This could result from sensory, motor, or reward components of task performance common to all of the quadrants. Alternatively, this could represent firing changes selective for when the rat occupied the arena center or any extended region that had a four-way axis of symmetry (such as a concentric annulus). Although a significant trajectory factor could occur for a unit with very high selectivity for a location along the trajectory between corner and center in only one quadrant, the ANOVA interaction factor would also be significant.

To pinpoint the sources of significant differences found with the $4 \times 8$ ANOVA, further analyses were pursued. One-way ANOVAs compared (transformed) firing rates between the four corners for each of the eight respective $250 \mathrm{msec}$ periods that composed the center-corner trajectory (one-way ANOVA across quadrants). Four additional one-way ANOVAs compared the firing rates between the eight time periods for each of the quadrants (one-way ANOVA across trajectories). Finally, in cases of significant $F$ values in these tests, the Student-Newman-Keuls (SNK) pairwise comparison for unequal repetitions (Steele and Torrie, 1960, p 114) determined precisely which measures were unequal at a significance level of $p<0.05$.

In the $4 \times 8$ ANOVA, the inexact synchronization of trajectories would tend toward type II errors in the form of unjustified rejection of trajectory effects since peaks in movement synchronized firing would become diffuse. More serious errors could result in the one-way ANOVAs, but these were only performed in the case of significance in the $4 \times 8$ ANOVA.

The $4 \times 8$ ANOVA and the one-way ANOVA across quadrants were carried out for both the intra-arena and extra-arena frames of reference. Since the photodetectors were attached to the arena, all behavioral data were collected in the intra-arena reference frame. To test if unit activity was selective for the rat's position in the extra-arena reference frame, the data were recomputed (cf. Speakman and O'Keefe, 1990) by accumulating the data for visits to the corners of the arena as identified by their position relative to the extra-arena reference frame. Thus, the data recorded while the rat was at corner $A$ of Figure $2 E$ (prior to arena rotation) were accumulated with the data recorded at corner $B$ of Figure $2 G$ (following the arena rotation), and so on.

Heading direction analyses. The orientation of the rat's head was determined trigonometrically from the positions of the red and blue bulbs. For analyses of location selectivity of directional firing, the arena floor was divided into a $3 \times 3$ array of squares. The rat usually occupied the center and four corner squares since they contained the water reservoirs. Firing rates were calculated by accumulating the total number of spike impulses as the rat's head was oriented toward each of 16 respective heading directions $\left(22.5^{\circ}\right.$ bin widths) and then averaging over the sampling periods. Statistical analyses included a $5 \times 16$ (reservoirs $x$ directions) factorial ANOVA, a one-way ANOVA across reservoirs for each heading direction, a one-way ANOVA across heading directions for each reservoir, and SNK pairwise comparisons. The same significance levels were used as above.

\section{Results}

Unit activity related to the rat's position

Location-selective cells. The unit of Figure 3 fired at $34 \mathrm{imp} / \mathrm{sec}$ during the $250 \mathrm{msec}$ period immediately following the rat's 

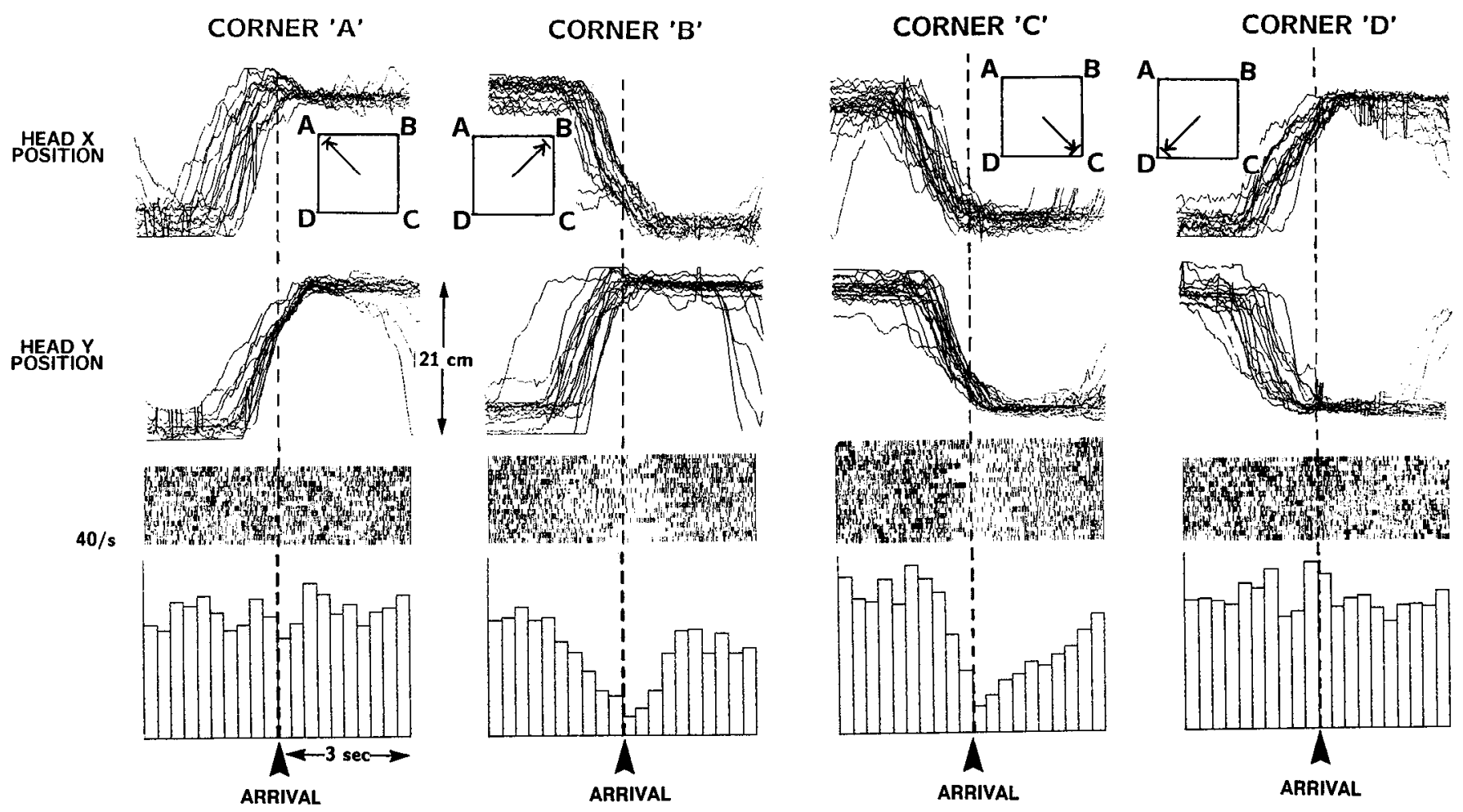

Figure 4. Head displacements and unit activity for the same cell as Figure 3 but for $3 \mathrm{sec}$ prior to and following the rat's arrival at the corner reservoirs ( $300 \mathrm{msec}$ bin width). The unit's firing rate remains significantly lower for the $1500 \mathrm{msec}$ period following the rat's arrival at corners $B$ and $C$ as compared to $A$ and $D$ (SNK, $p<0.05$ ), but this significant reduction in firing rate persists for the period 1500-2250 msec after the rat's arrivals at corner $C$ only (SNK, $p<0.05$ ). Note that no head displacements occur during these intervals.

arrival at corner $\mathrm{D}$, but only fired at 4.7 and $5.9 \mathrm{imp} / \mathrm{sec}$ for the same period after arrivals at corners $B$ and $C$ [one-way ANOVA across corners, $p<0.005, F=47.9, \mathrm{df}=(3,68)$; SNK, $p<0.01$ for differences between corners $\mathrm{B}$ vs $\mathrm{A}$ and $\mathrm{D}, \mathrm{C}$ vs $\mathrm{A}$ and $\mathrm{D}$; $p<0.05$ for D vs. A for this period]. The one-way ANOVA also revealed significant differences between firing rates at the four corners for all intervals tested except -1000 to $-750 \mathrm{msec}$. The SNK analysis showed significant pairwise differences between corners for all intervals from $250 \mathrm{msec}$ prior to and 1000 msec after arrival of the rat. The same analyses for the extraarena reference frame show no significant differences in firing rates at the four corners for the $250 \mathrm{msec}$ time interval following corner arrivals $[p>0.05, F=3.37, \mathrm{df}=(3,68)]$ and no significant pairwise differences between corners in the SNK test for any of the other intervals tested. This indicates that the intramazc reference frame best describes the data.

In the $4 \times 8$ factorial ANOVA for this unit, significant values of $F$ were found for all factors [ $p<0.005$ for all: quadrants, $F$ $=75.5, \mathrm{df}=(3,572)$; trajectory, $F=6.8, \mathrm{df}=(7,572)$; interaction, $F=3.6, \mathrm{df}=(21,572)]$. The significant interaction effect indicates that although this cell's firing rate decreased as the rat moved from center to corner, there was also a difference in this effect in the four quadrants of the arena. For the same analysis in the extra-arena reference frame, $F$ for the quadrants factor was also significant $(p<0.005)$ but was more than 10 times lower in magnitude $[F=4.5, \mathrm{df}=(3,572)]$ than for the intraarena analysis (above). The significant effect for the analysis in the extra-arena frame of reference is likely to be derived from the fact that there were two corners associated with significant decreases in firing rate and that for the original position and certain $90^{\circ}$ rotations of the arena, these same corners, in the extra-arena frame of reference, still were associated with a decrease in firing rate (not shown).

To determine if the firing rate decrease persisted throughout the entirety of the rat's visits to corners B and C, the same analyses were performed over a longer $6 \mathrm{sec}$ period (Fig. 4) and the bin widths for the ANOVA trajectory factor were $750 \mathrm{msec}$ rather than $250 \mathrm{msec}$. The firing rate still decreased significantly as the rat arrived at corners B and C [one-way ANOVA across trajectories; corner $\mathrm{B}, p<0.005, F=18.7, \mathrm{df}=(7,136)$; corner $C, p<0.005, F=25.2, \mathrm{df}=(7,160)]$, and this effect persevered for the $2250 \mathrm{msec}$ period following the arrival of the rat at corner $\mathrm{C}$ (SNK, $p<0.01$ for all pairwise tests). At corner $\mathrm{B}$, the firing rate decreased significantly during the period that began and ended earlier than for corner C (see Fig. 4). Thus, the firing rate decrease occurred as the rat performed different behavioral sequences in quadrants $B$ and $C$. The unit's firing rate also returned to the average value while the rat remained at water reservoirs $\mathrm{B}$ and $\mathrm{C}$. The plots of Figure $5 \mathrm{~A}$ confirm that the average firing rate was higher when the rat was at corners $\mathrm{D}, \mathrm{A}$, and the center than at corner $\mathrm{C}$, but the effect at corner B is not evident (darker squares indicate higher firing rates).

This unit's spatial selectivity is not likely to be related to possible differences in the rewards offered at the four corners, since the water volume had been calibrated and the rat showed no apparent preferences for any of the reservoirs as might be evidenced by repeated or prolonged visits to certain reservoirs. The difference in the timing of the unit response between quadrants $B$ and $C$ also argues against a reward correlation.

Eight units had significant values of $F$ for the quadrant factor 
TIME OCCUPIED A
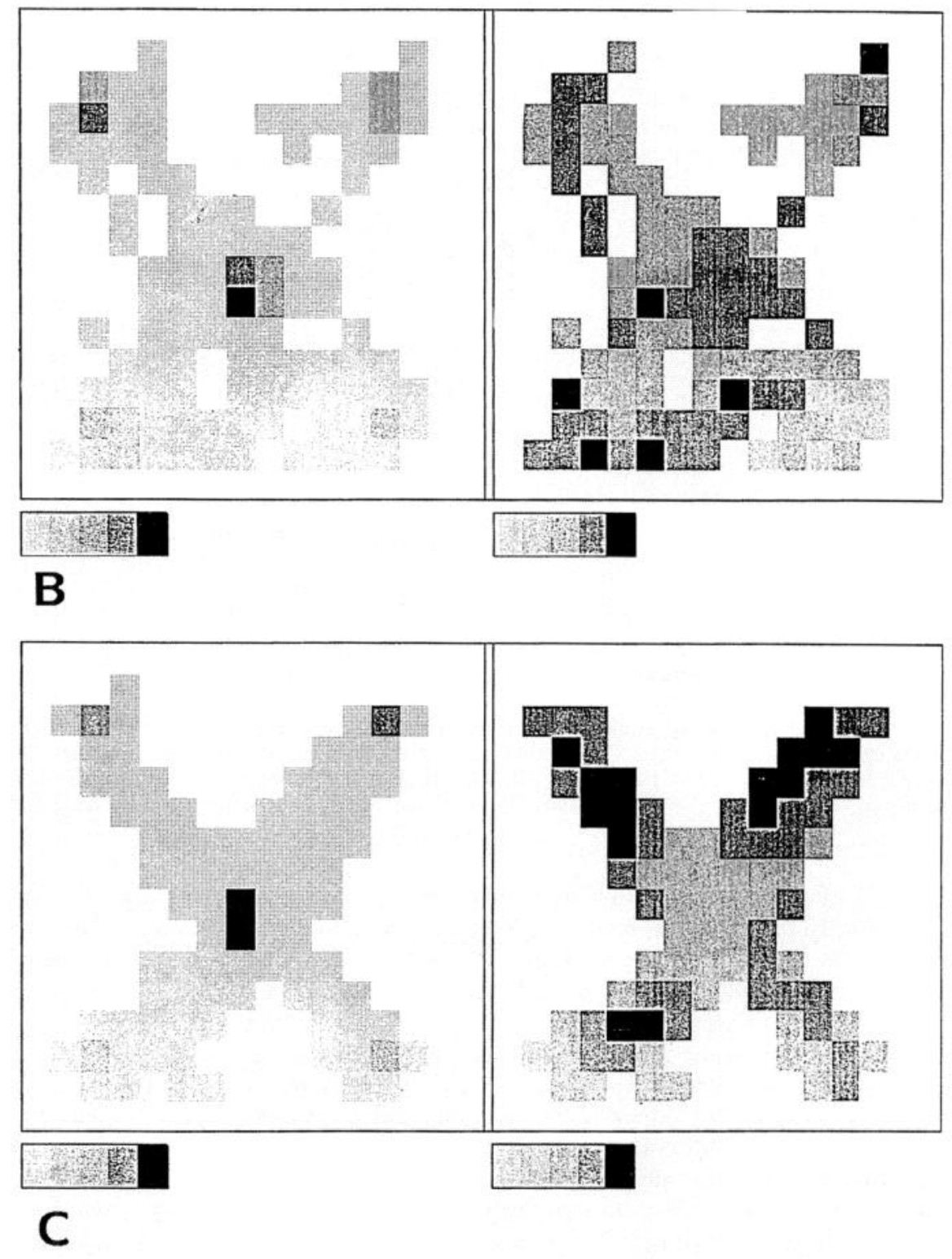

Figure 5. For three different recording sessions, plots from an overhead view of the arena of the amount of time that the rat spent in different locations (left) and the average firing rate of a unit recorded as the rat occupied these positions (right). All plots are in the intraarena frame of reference. The scales below each figure calibrate the shading intensities indicating time or firing rate. $A$, The different levels of gray correspond to equal fractions of the maximum occupancy time (91 sec). Thus, the white squares of the occupancy plot represent total visits lasting in the range of $0-18 \mathrm{sec}$ (one-fifth of the maximum). In the firing rate plot, white squares represent visits of less than $2 \mathrm{sec}$ (a threshold to avoid spurious peaks) and the rates in the remaining squares are divided into quartiles of the maximum rate $(40 \mathrm{imp} / \mathrm{sec})$. These data are from the same unit shown in Figures 3 and 4. Averaged over the entire session $(1090 \mathrm{sec})$, the firing rates appears highest when the rat was in corner $D$, the center, and in corner A. B, An example of a different location-selective unit. Maximum occupancy, 219 sec; maximum firing rate, $46 \mathrm{imp} / \mathrm{sec}$; session lasted $1693 \mathrm{sec}$. $C$, Data from the direction-selective unit shown in Figures 6 and 7. The firing rate increased up to $18 \mathrm{imp} / \mathrm{sec}$ when the rat occupied those positions where it tended to face in the preferred direction. Maximum occupancy, $219 \mathrm{sec}$; maximum firing rate, $18 \mathrm{imp} / \mathrm{sec}$; session lasted $1626 \mathrm{sec}$. The inappropriateness of statistical analysis to this representation of the data is detailed in Materials and Methods.
FIRING RATE

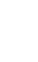




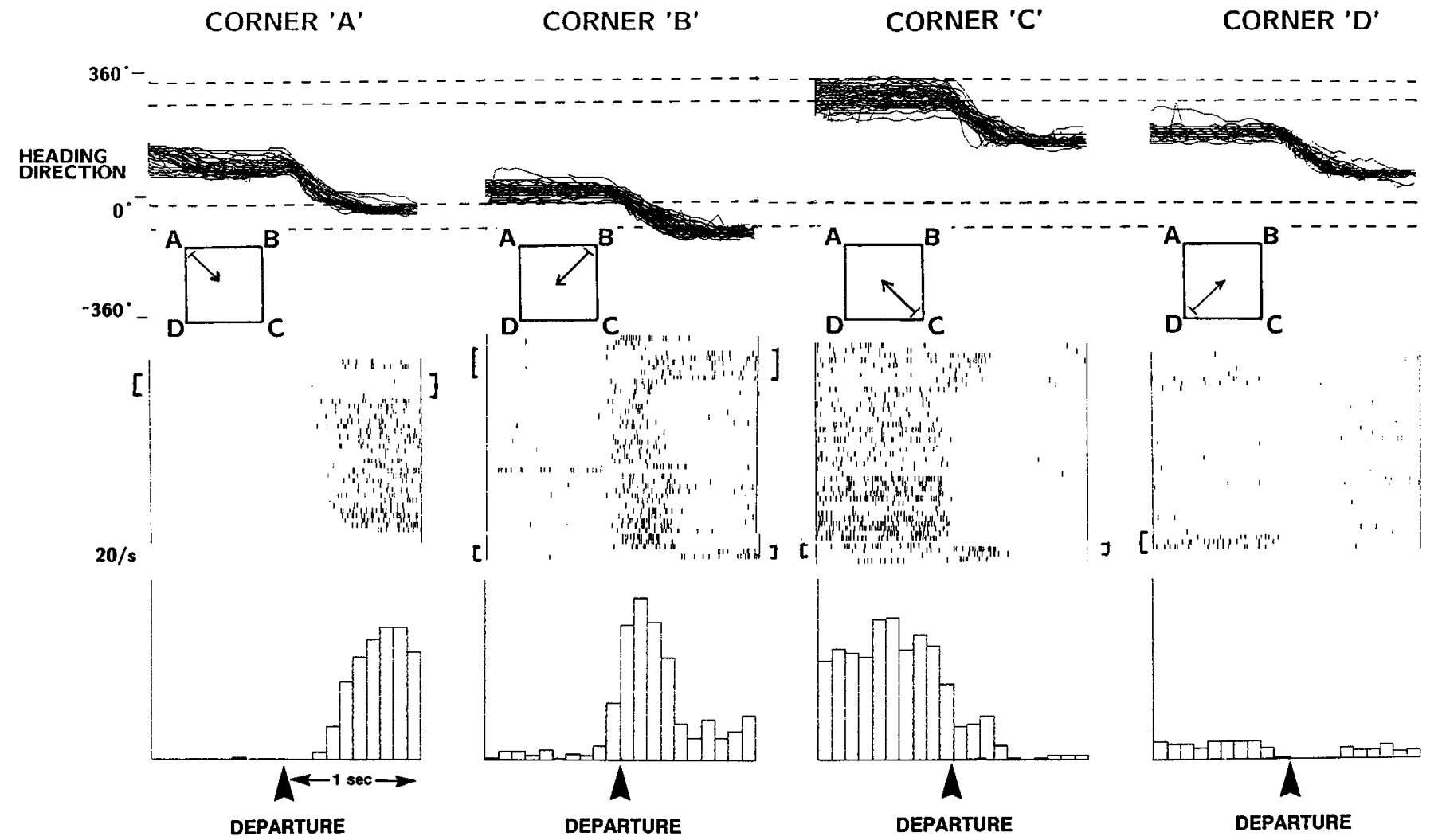

Figure 6. Heading direction and unit activity are plotted in synchrony with the instant that the rat departed from each of the four corner reservoirs; the trajectories are schematized in the insets. In the upper traces of the rat's heading direction, the horizontal dashed lines highlight the "preferred direction" that corresponds to the cell firing shown in the bottom traces.

in the $4 \times 8$ factorial ANOVA and at least one significant SNK test for the intra-arena reference frame; these units are considered location selective. In an earlier pilot experiment conducted with the room lights on and no arena rotations, two more location-selective units were recorded; these are not further discussed here. The locations associated with firing rate changes did not seem be located in one particular quadrant. For example, in the cell shown in Figure $5 B$, the firing rate reached a maximum of $40 \mathrm{imp} / \mathrm{sec}$ prior to the rat's departure from corner B (oneway ANOVA, $p<0.005$; SNK, $p<0.05$ ), although this corner was associated with a reduction in firing rate in the cell of Figure $5 \mathrm{~A}$. In computations in the extra-arena reference frame, two of the location-selective neurons also had significant values of $F$ for the $4 \times 8$ ANOVA, but these were much lower than for the intra-arena reference frame analysis (see above).

In six of the eight location-selective units, including the example above, the trajectory factor of the $4 \times 8$ ANOVA was also significant. In these cases, the subsequent one-way ANOVA and SNK pairwise tests always showed that this effect was not significant in all of the quadrants. As in the example of Figure 3, this indicates that the location-selective change in firing rate occurred for only a part of the time that the rat was in the place in question. Two of the eight units had significant $F$ values in the $4 \times 8$ ANOVA for the quadrant factor for corner arrivals only, two for corner departures only, and four for both arrivals and departures.

Heading direction-selective activity. The unit shown in Figure 6 fired only as the rat's head orientation was parallel to the axis running from corner $\mathrm{A}$ to corner $\mathrm{C}$. This will be called the "preferred direction" for this cell. In Figure 6, as soon as the rat oriented its head in the preferred direction while departing from corner $A$, the cell began to fire at about $12 \mathrm{imp} / \mathrm{sec}$, but at corner $\mathrm{C}$, the cell fired as the rat was standing still prior to departure. At corner B, as the rat typically started to depart by rotating clockwise (downward deflection in heading direction trace), the cell fired at about $15 \mathrm{imp} / \mathrm{sec}$, just as the rat's head was momentarily oriented in the preferred direction. This is confirmed by the lack of correlation between this unit's activity and head displacement movements [factorial ANOVA across departure trajectories, $p>0.1, F=0.89$, $\mathrm{df}=(7,1324)]$.

In Figure 7, this unit's firing rate appears highest when the rat's head was oriented in the range of $292.5-337.5^{\circ}$ (bins 14 and 15) at each of the water reservoirs (one-way ANOVA across heading directions for each reservoir, $p<0.005$; SNK, $p<0.05$ for pairwise comparisons). When the rat was at corner $\mathrm{B}$, this unit fired selectively as the rat's head was oriented parallel to the axis between corners $\mathrm{A}$ and $\mathrm{C}$ rather than as the rat faced corner $\mathrm{C}$. In the latter case, the maximal firing would have been found for bins 12 or $13\left(247.5-292.5^{\circ}\right)$, but was not (SNK, $p>$ 0.05 ). The slight variation in preferred direction measured at the different reservoirs is within the range of precision of the tracking system (see Materials and Methods).

The location selectivity plot for this unit (Fig. $5 C$ ) indicates that the averaged firing rate was as high as $18 \mathrm{imp} / \mathrm{sec}$ when the rat's head was at corner $\mathrm{C}$ and near the center. This analysis alone would give the impression that this is location-selective firing. The other analyses indicate that this effect derives instead from the fact that, according to the requirements of the task, it 
Figure 7. For the same unit as in Figures $5 C$ and 6 , the firing rate is displayed as a function of the rat's heading direction averaged for the total time that the rat was at each of the five water reservoirs. Error bars show the SEMs. The analysis is in the intra-arena frame of reference. The vector pointing from corner A to corner B is considered as $0^{\circ}$, and the convention of counterclockwise as positive is adopted. There are 16 bins; bin widths are $22.5^{\circ}$. Heading directions for which there were an insufficient number of measurements $(<500 \mathrm{msec})$ are shown as negative deflections; one-way and pairwise statistics for these are not presented. Peak firing rates were found for bins 14 and 15 that correspond to heading directions of $292-337^{\circ}$. The unit activity accompanying heading directions of $225^{\circ}$ correspond to shifts in the directional selectivity of the unit (see bracketed regions in Fig. 6).
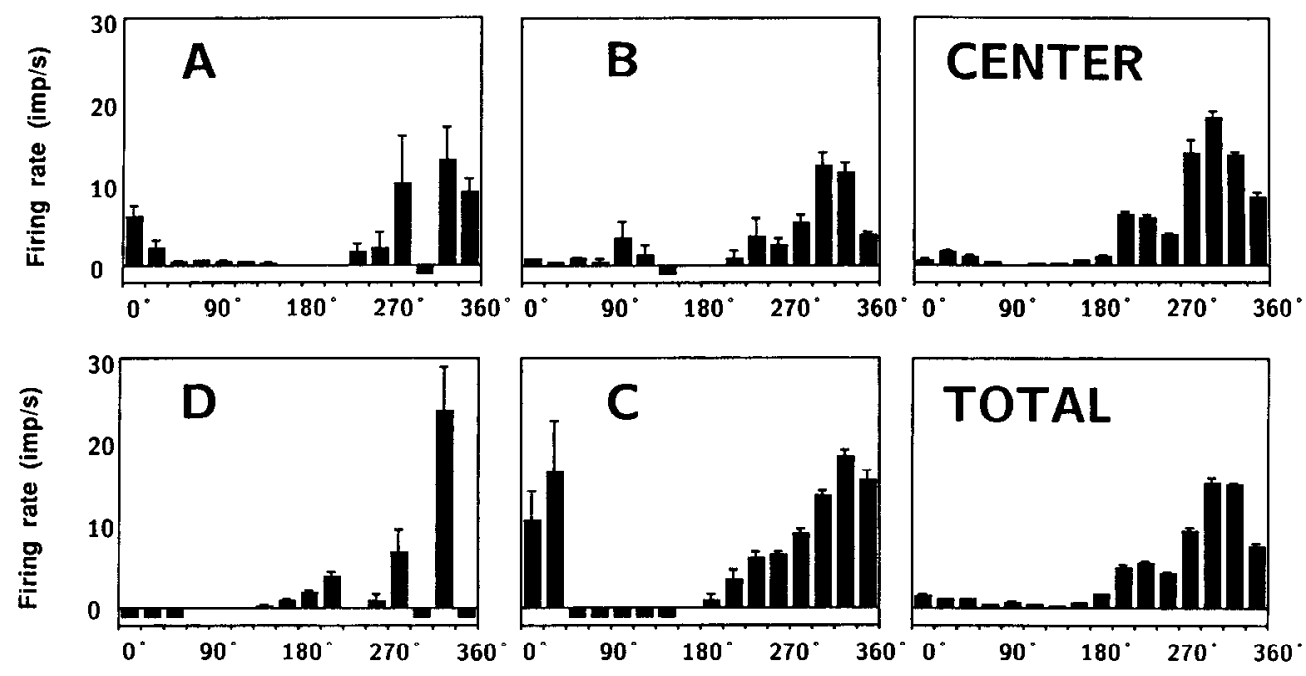

was in these locations that the rat's head was most likely to be oriented toward the preferred direction.

The preferred direction of the cell was relative to the intraarena reference frame. The factorial ANOVA of corner departures showed significant differences between quadrants $[p<$ $0.005, F=63.7, \mathrm{df}=(3,1324)]$ and a significant interaction effect $[p<0.005, F=47.0, \mathrm{df}=(21,1324)]$ in the intra-arena frame of reference. However this analysis in the extra-arena reference frame yielded an insignificant value of $F$ across quadrants $[0.025<p, F=2.9, \mathrm{df}=(3,1324)]$. Two other directionally selective units were recorded.

Although for six arena rotations the directional selectivity rotated with the arena, on two occasions the unit shifted its preferred direction by $90^{\circ}$ (see brackets next to raster displays in Fig. 6). These shifts remained stable throughout the following trials until the next rotation of the arena. In these cases of shifts
CORNER 'A'

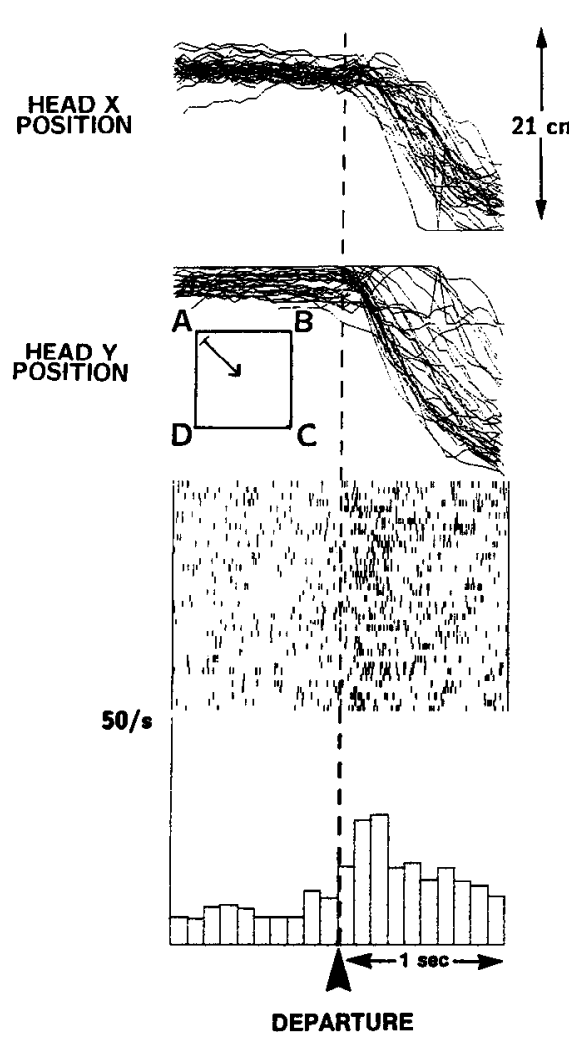

CORNER 'B'

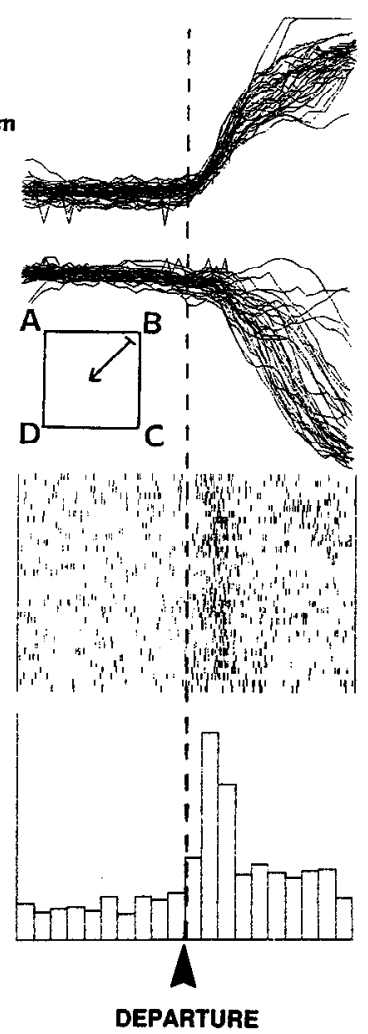

CORNER 'C'
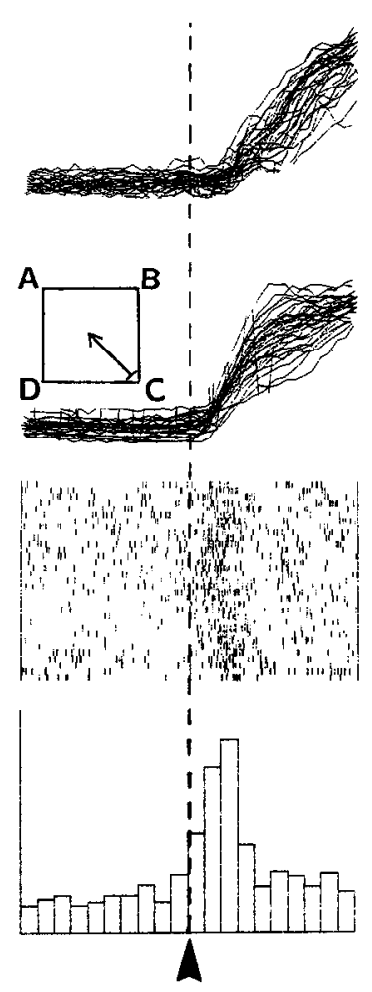

DEPARTURE

\section{CORNER 'D'}
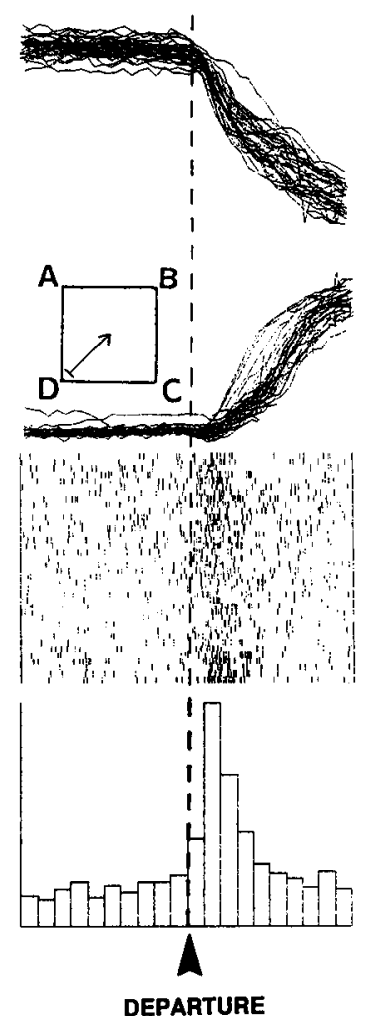

Figure 8. This unit's firing rate increased for a $250 \mathrm{msec}$ period as the rat started to depart from the reservoirs. The unit maintained the same firing rate while the rat was at rest prior to departure and while the rat was running following the departure. 

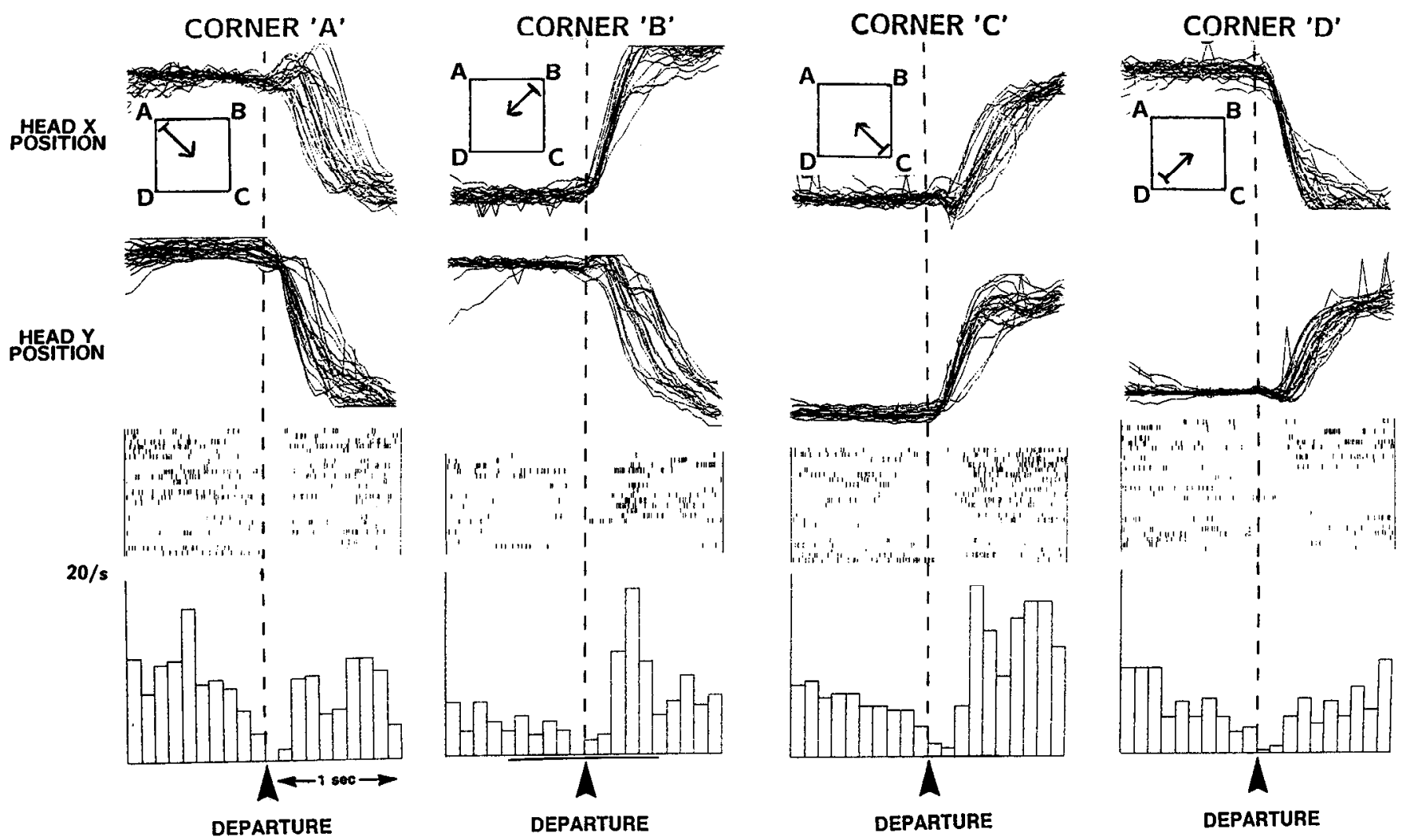

Figure 9. This unit stopped firing as the rat started to leave the reservoirs. The unit fired while the rat was at rest prior to departure and also while the rat was running following the departure.

in directional selectivity, the rat had prematurely departed from the central reservoir while the arena was still being rotated.

\section{Unit activity changes related to head displacement movements}

Movement onset. In Figure 8, this cell's firing rate increased from $6 \mathrm{imp} / \mathrm{sec}$ to about $40 \mathrm{imp} / \mathrm{sec}$ as the rat initiated departures from the corner reservoirs. This also occurred at the center reservoir (not shown). The $4 \times 8$ ANOVA for the departures from the corners was significant for the trajectory factor $[F=$ $113.0, \mathrm{df}=(7,1156)]$ but not for the quadrant factor $[p<0.1$, $F=0.85$, df $=(3,1156)]$. In the one-way ANOVA across trajectories, significant effects occurred at each of the reservoirs $[F(\mathrm{~A})=19.9, \mathrm{df}=(7,296) ; F(\mathrm{~B})=30.4, \mathrm{df}=(7,280) ; F(\mathrm{C})=$ $29.1, \mathrm{df}=(7,256) ; F(\mathrm{D})=42.8, \mathrm{df}=(7,296)]$ and the firing rate in the $250 \mathrm{msec}$ period following departure was significantly higher than the other seven periods tested for each corner (SNK, $p<0.01$ ). Although the rat continued to move for almost $1 \mathrm{sec}$ following the departure trigger, the increase in cell activity lasted only $250 \mathrm{msec}$, which corresponds to the period of initiation of movement. At corner A, this effect lasted an additional 250 msec, but may be accounted for by a few irregular trajectories there.

In Figure 9, a different cell's firing rate decreased as the rat departed from the corner reservoirs toward the center of the arena. This activity decrease also occurred upon departures from the center (not shown). The $4 \times 8$ ANOVA of corner departures shows significant effects for the trajectory factor $[F=7.1, \mathrm{df}=$ $(7,748)]$ and also for the interaction factor $[F=2.1, \mathrm{df}=(21,748)]$ but there is no quadrant effect $[p>0.1, F=0.91, \mathrm{df}=(3,748)]$. The one-way ANOVA shows a significant effect for the trajec- tory factor for departures from reservoirs $\mathrm{B}[F=5.7$, $\mathrm{df}=$ $(7,152)]$ and $\mathrm{A}[F=4.9, \mathrm{df}=(7,192)]$ but not corners $\mathrm{D}[0.01$ $<p, F=2.7, \mathrm{df}=(7,200)]$ or $\mathrm{C}[p>0.1, F=1.4, \mathrm{df}=(7,176)]$. This effect appears in the histograms as an increase in firing rate in the fourth bin after the synchronization point; this corresponds to when the rat was running. Thus, this unit has a firing rate reduction and rebound upon movement onset that is significant in only two of the corners.

Movement execution. Figure 10 shows a different cell's activity profile that combines some of the movement correlates of the cells of Figures 8 and 9 . Here the traces are synchronized with the midpoint of the trajectory. As the rat initiated the head displacement, the firing rate increased. Following this, as the rat was moving, the cell stopped firing for a period lasting $100-$ $400 \mathrm{msec}$. In the $4 \times 8$ ANOVA for corner arrivals, only the trajectory factor is significant. This unit was recorded simultaneously with that of Figure 9.

For another cell (Fig. 11), the plots are also synchronized with the midpoint of the trajectory. This unit's firing rate was about $8 \mathrm{imp} / \mathrm{sec}$ while the rat ran between the reservoirs, but was inactive when the rat initiated the movement or was at rest. In the $4 \times 8$ ANOVA for departures, the trajectory factor is significant $[F=27.5, \mathrm{df}=(7,468)]$. A total of six movement-selective cells were recorded, of which two had location-selective effects.

\section{Other response types}

Another group of cells were largely silent during the experiments. However, they became active only after the arena was rotated (Fig. 12). When the headstage lights were turned on following the rotation, an artifactual pulse was picked up by the 
CORNER 'A'

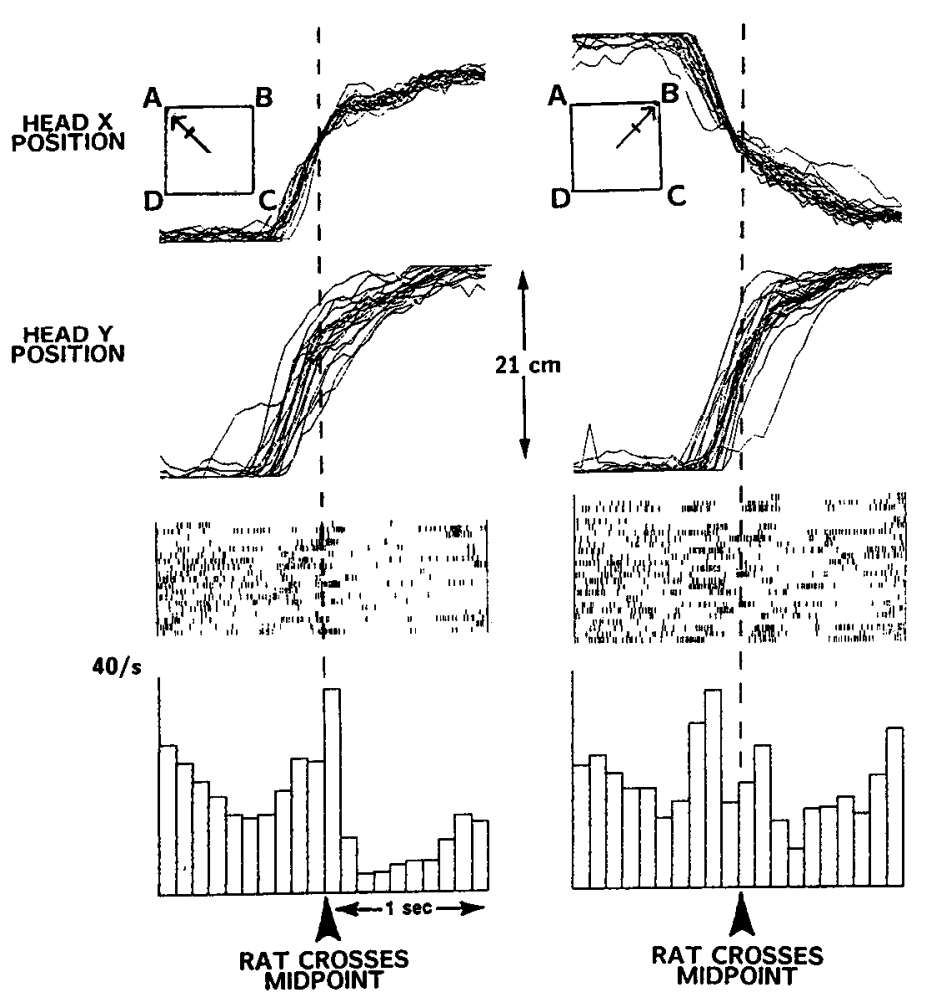

CORNER ' $C$ '
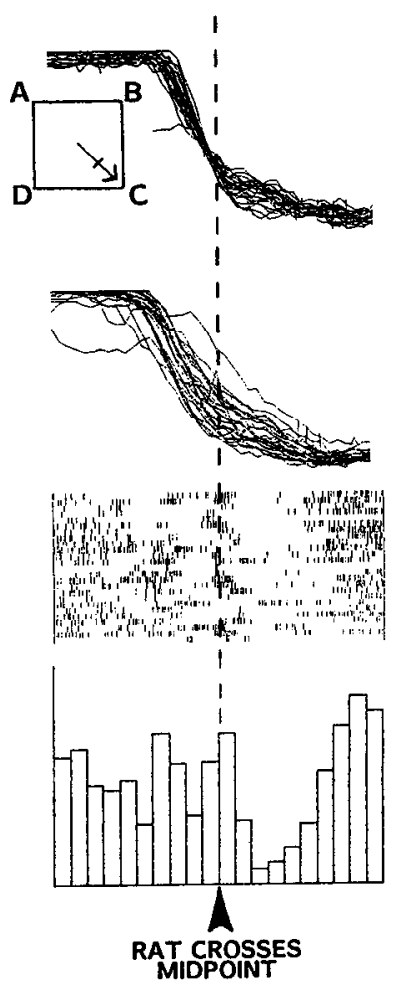

CORNER 'D'

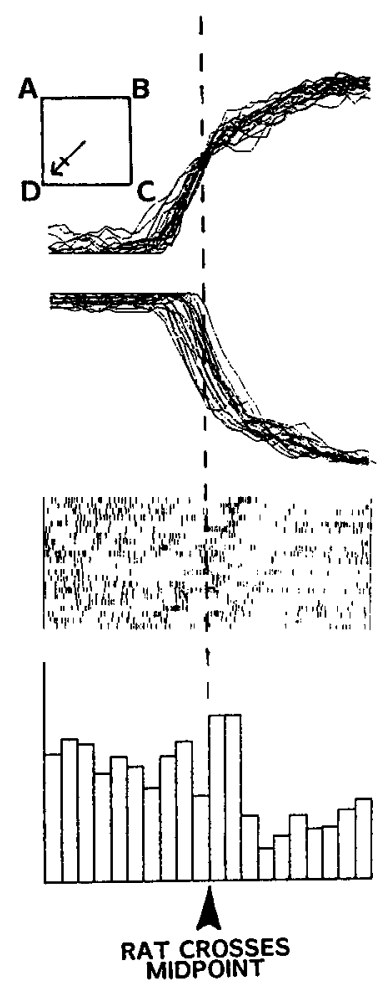

Figure 10. These plots are synchronized with the instant that the rat crossed the midpoint while running from the center to the corners. The raster display shows that the unit fires in bursts and pauses while the rat was moving. While the rat was at rest at the center reservoir (first 500 msec of trace) the cell also fired at about $20 \mathrm{imp} / \mathrm{sec}$.

preamplifiers; this prevented measurement of the latency of the neuronal response. The duration of activity in these cells ranged on the order of 10-100 seconds. In one case, where there was a mechanical problem with rotating the arena, one such unit was also activated after the room lights were turned on and the experimenter entered the room. Two units had silent periods lasting more than half of the recording session and hence were excluded from the analyses.

Many cells with firing rates less than $1 \mathrm{imp} / \mathrm{sec}$ were encountered. Of these, nine were analyzed thoroughly and found to have no discernible synchronization with the rat's movements and position or the reward delivery. The low numbers of impulses did not permit statistical analyses.

\section{Summary}

Thirty units in the right rostromedial dorsal striata of five rats were recorded and analyzed. The reconstructions of the electrode recording tracks and the unit properties are shown in Figure 13. The location-selective units are indicated by " $L$ " in the figure (eight units). In a pilot experiment (see above), two more location-selective units were found in another rat with an electrode track in the same region as the rostralmost (left) penetration in this figure. Another group of cells were only active as the rat faced a certain direction (three units, "D"). A third group increased their firing rates up to fivefold or completely stopped in synchrony with the onset or execution of head displacement movements (six units, " $M$ "). Another group of cells were inactive while the rat performed the task but became tonically active after the arena was rotated (three units, " $T$ "). Nine units with extremely low firing rates $(<1 \mathrm{~Hz})$ were analyzed and had no discernible correlates with movement or position (not indicated). Finally, two units had firing rates that fluctuated over cycles lasting several minutes (not indicated).

\section{Discussion}

Location selectivity in striatal units is reported here for the first time. This low spatial resolution suggests that comparisons among an ensemble of such neurons would be necessary to determine the precise location of the rat. Alternatively, like the broad spatial selectivity of hippocampal theta cells (McNaughton et al., 1983; Kubie et al., 1990) or of medial entorhinal neurons (Quirk et al., 1992), perhaps other neurons in the same network as these striatal neurons could further resolve this signal and have more highly resolved spatial tuning.

Though hippocampal theta cells have large firing fields, their primary behavioral correlate is with active displacement, as well many other vigorous behaviors (for reviews, see Bland, 1986; Miller, 1991). In contrast with the theta cells, but similar to hippocampal pyramidal cells, the location-selective striatal neurons fired during many behaviors including moving, standing still, and drinking. In contrast with hippocampal pyramidal cells, the location-selective changes in firing rate did not last for the entire period that the rat was at a particular place. One interpretation is that these striatal neurons are involved in the sequencing of spatial behavior rather than only the rat's position in space. Since these responses could occur at several different parts of the behavioral sequence for any given unit, this also suggests that a type of neuronal ensemble coding is taking place.

"Heading direction" cells reported here represent for the first time a behavioral correlate of striatal units that cannot be as- 
CORNER 'A'

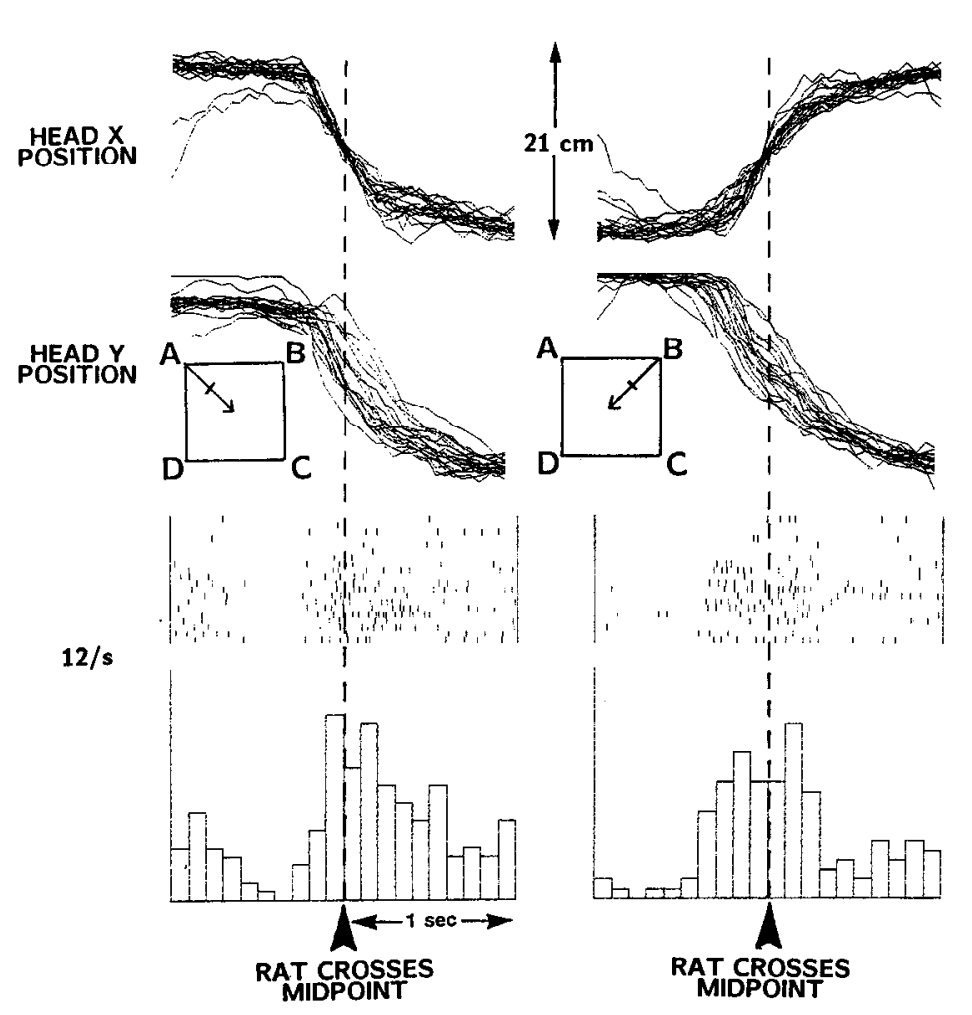

CORNER ' $C$ '

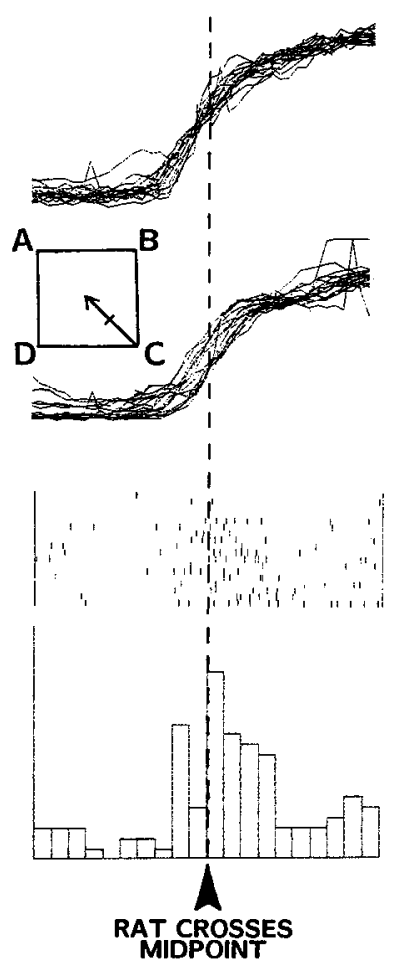

CORNER 'D'

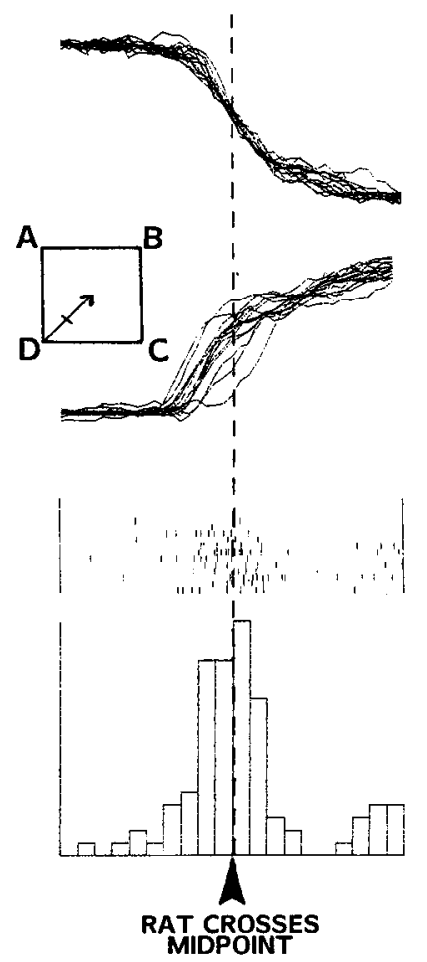

Figure 11. This cell fired only while the rat was running between water reservoirs. These plots are synchronized to the instant that the rat crossed the midpoint between the reservoirs.

sociated with specific ongoing or anticipated movements. Other non-movement-related responses previously found in monkey striatal neurons were related to anticipation of sensory stimuli, but these stimuli also triggered responses in the behavioral task and thus had a strong association with movements (e.g., Hikosaka et al., 1989b). Similarly, reward related responses in monkey striatum (Apicella et al., 1991) could be associated with the task response movements or the movements of consuming the reward. Although only three directional-selective units were recorded and analyzed here, this finding has been confirmed elsewhere in rats performing in an eight-arm radial arm maze (A. M. Lavoie and S. J. Y. Mizumori, personal communication). In stationary rats performing leftward or rightward head rotations toward auditory cues, striatal units are selective for turning direction (Gardiner and Kitai, 1992); however, this could have been due to sensory or motor differences between left and right head turns. In the monkey, certain classes of units are selectively active according to the direction of arm movements regardless of the associated muscle activity pattern (Crutcher and DeLong, 1984; Mitchell et al., 1987). In experiments where monkeys manipulate a joystick to move a cursor on a CRT display with control in standard or inverted (rightward movements cause leftward cursor shifts) modes (Alexander and Crutcher, 1990b), some putamen units were selectively active during preparation for cursor movements in one direction, even though this could involve arm movements in either direction. In these experiments, it is not clear if the spatial frame of reference of the movement directional selectivity is centered at the monkey or

\section{WATER REWARD
DELIVERY}

UNIT ACTIVITY

ARENA TURNS

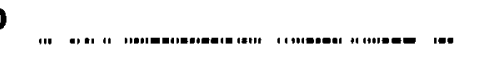
g 
Figure 13. Histological reconstructions of electrode penetrations in the striatum. Tracings are in the frontal plane after the atlas of Paxinos and Watson (1986). Heavy vertical lines indicate the electrode track. Horizontal bars show the limits of the locations that recordings were made as estimated by electrode advances. Adjacent to the tracks, the unit properties are indicated by letters that are ordered in the sequence that the units were encountered: $S$, location selective; $D$, direction selective: $M$, movement related; $T$, arena rotation related.
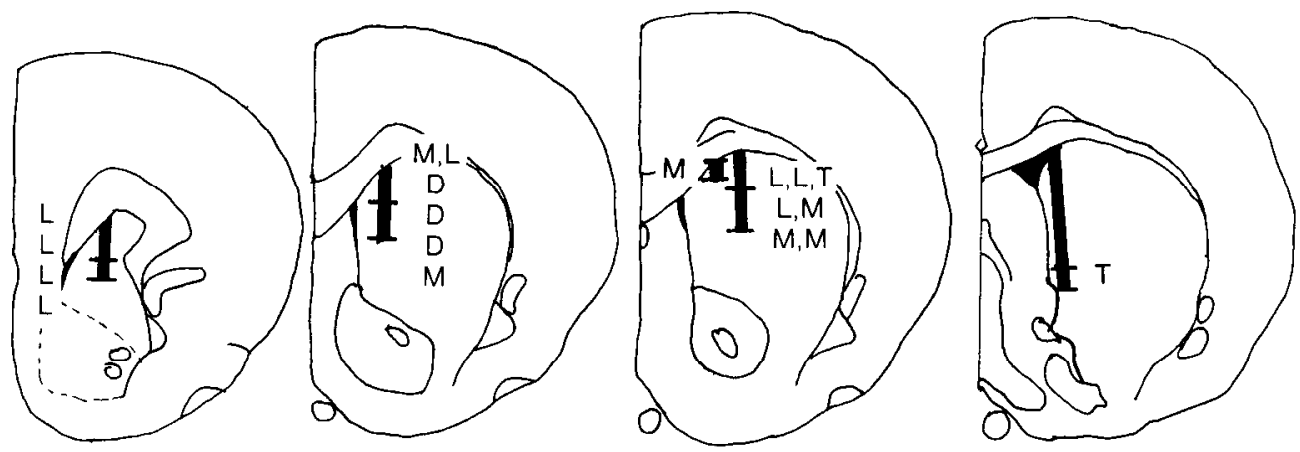

on some external referent, since the targets always retained the same spatial position relative to the monkey.

Units selective for heading direction have been found in the dorsal postsubiculum (Taube et al., 1990a), retrosplenial cortex (Chen et al., 1990), and lateral dorsal thalamic nucleus (Mizumori and Williams, 1991) of the rat. Similar to postsubicular neurons recorded in rats running after food pellets in a circular arena (Taube et al., 1990a), our striatal units fired selectively as the rat's head was directed in a certain compass orientation regardless of where the rat was in the arena and irrespective of the local view at that location in contrast with rat (McNaughton et al., 1983) and monkey (Rolls and O'Mara, 1992) hippocampal cells. This response could not derive simply from visual cues associated with a single stimulus or landmark, but rather must depend upon an ensemble of cues relating the position of the walls of the arena to the current position and orientation of the rat.

\section{Cue control and reference frames of neuronal spatial responses}

There seems to be a discrepancy between the principal spatial referent of the striatal units in the present experiment and that reported elsewhere for hippocampal and postsubicular units (references above). The latter results indicate that environmental cues on the periphery of the testing area exert powerful effects upon the spatial correlates of neuronal activity. In the hippocampal and postsubicular cells, rotation of cues on the periphery or outside of the arena resulted in shifts by the same angle in the respective firing field or preferred direction (Muller et al., 1987b; O'Keefe and Speakman, 1987; Kubie et al., 1990; Taube et al., 1990b). In all of these experiments, the rat was removed from the room while the cues were moved and then the rat is rotated in a sealed box before being returned to the arena. In other experiments where the rat's body was supported (Markus et al., 1990) or held in the experimenter's hands (Taube et al., $1990 \mathrm{~b}$ ), and then passively moved, the directional selectivity of the postsubicular and retrosplenial units remained stable with respect to cues on the wall. In contrast, in the present experiment, the striatal units' directional selectivity rotated with the rat and the arena, and was not influenced by the dominant visual cue. The fundamental difference between the two experiments may be the inertial information that was provided in the present experiment, where the rat was rotated passively with its feet on the floor. This would have the effect of stimulating the rat's vestibular organs and the supporting limbs during the rotation. A preliminary conclusion, then, is that the strong influence of cues on the periphery and outside the arena on spatially selective unit activity can be reduced in the presence of conflicting inertial cues. Matthews et al. (1989) showed that rats that were rotated while standing could reorient toward a fixed position, and that vestibular lesions impair this performance. Alternatively, spatially selective activity in the striatum and hippocampus may differ fundamentally with regard to their dominant cue referents. Olfactory cues are not likely to have been a dominant influence on the neural activity since the arena was cleaned regularly, and the location-selective firing was over broad areas and correlated with only certain movements of the rat in the location; for the direction-selective neurons, the preferred direction could shift relative to the arena and possible olfactory cues.

Mittelstaedt and Glasauer (1991) showed that the patterns of errors made by walking gerbils subjected to experimental rotations of the arena demonstrate that both vestibular and muscle inputs contribute to navigation behavior. These errors may be reflected in the present experiment by those cases of $90^{\circ}$ shifts in the striatal neuron's directional selectivity following those arena rotations where the rat had prematurely left the center (Fig. 6). This would have generated proprioceptive and kinesthetic signals that were no longer indicative of the actual displacement of the rat.

Movement initiation cells. Units with firing rate changes in synchrony with the onset and execution of intentional movements of the forelimb or the eye have previously been found in monkey caudate and putamen (Hikosaka et al., 1989a; see also reviews by Schultz, 1989; Rolls and Johnstone, 1991; and references in introductory remarks) and to head movements in the striatum and globus pallidus of stationary rats (Gardiner and Kitai, 1992). A principal new, though not unexpected, finding here is that striatal units also have increases or decreases in firing rate synchronous with the initiation or execution of locomotor movements. The present recordings were in more rostral parts of the striatum than previous studies, a region likely to correspond to the caudate nucleus in the monkey. Although in the present study muscle activity was not monitored, recording studies in the monkey indicate that unit activity in the striatum or in the globus pallidus is often not correlated with activation of specific muscle groups (Crutcher and DeLong, 1984; Mitchell et al., 1987), a principal target of striatal efferents.

The theta cells of the hippocampal formation (see above) also are active during the execution of displacement movements. The striatal movement cells differ principally in that they fire selectively during either movement initiation, active running, or arrival, but not during all as do theta cells (references above).

Postrotational responses. The cells that began firing only after rotations of the arena could be interpreted as responses to novel or changed situations or perhaps set-shifting. There seems to be no clear sensory aspect to this response since the after-nystagmus that would result from the rotations would be of shorter duration 
than this unit activity. If this type of cell is indeed participating in "set-shifting," or even an affective response to the rotation, then such activity correlates could be easily misinterpreted in nonautomated experiments with experimenter-produced stimuli.

Cell identification and possible inputs to these cells. In the striatum, $95 \%$ of the neurons have medium spiny morphology, are GABAergic, and send out efferent projections (Wilson, 1991), while the remaining group are mostly large cholinergic interneurons, which fire tonically at very low rates (less than $1 \mathrm{imp} /$ sec; Wilson et al., 1991). Most of the cells recorded here had much higher average firing rates than this and, if not active, stopped firing completely rather than maintaining a low tonic discharge; thus, they are more likely to be medium spiny neurons. But even medium spiny striatal neurons with firing rates above $10 \mathrm{imp} / \mathrm{sec}$ have rarely been shown in striatal recording studies (e.g., Wilson and Groves, 1981). This could be because in the present work, the rat carried out a repeated series of selfinitiated displacements rather than resting in an immobilized state. Indeed, the firing rates of the neurons reported here fall within the range of less than $10 \mathrm{imp} / \mathrm{sec}$ during periods when the rat was at nonpreferred locations or facing nonpreferred heading directions, or was not initiating movements.

The location-selective unit activity could derive from the hippocampal system. A hippocampal-to-striatal pathway could pass through the cingulate cortex (hippocampal to cingulate projection: Swanson and Cowan, 1977; cingulate to striatal projection: Veening et al., 1980; McGeorge and Faull, 1989). The hippocampus projects directly to portions of the striatum more ventral than those recorded here (Kelley and Domesick, 1982; McGeorge and Faull, 1989), but the lateral entorhinal cortex, in addition to its hippocampal projections, sends outputs to the striatum (Swanson and Köhler, 1986).

The heading direction selectivity in the striatum could derive from direct inputs to the striatum from the retrosplenial cortex and dorsal postsubiculum (Groenewegen et al., 1987; McGeorge and Faull, 1989), both of which have been shown to have directionally selective cells in the rat (Chen et al., 1990; Taube et al., 1990).

Vestibular projections to striatum. The capacity for both location selectivity and directional selectivity can be derived from inertial information regarding self-displacement, especially under dark conditions. The horizontal semicircular canals and the otolithic organs, respectively, provide information about changes in heading direction and linear movements. The intralaminar nucleus of the thalamus could carry vestibular information to the striatum since vestibular projections to the intralaminar nucleus have been demonstrated in cat (Blum et al., 1979) and monkey (Liedgren et al., 1976; Magnin and Kennedy, 1979) and the intralaminar nucleus projects to the striatum in the rat (Jones and Leavitt, 1974; Kuypers et al., 1974; Nauta et al., 1974). Potegal et al. (1971) also demonstrated electrophysiologically the existence of a multisynaptic vestibular projection to the rat striatum that persisted after parietal cortex lesions.

Inertial stimuli are also generated during the onset and execution of active displacement movements. Thus, vestibular inputs could also contribute to unit activity associated with head movements.

\section{Implications of unit properties}

These cell activity correlates correspond to the motor and cognitive deficits that result from striatal lesions in experimental and pathological cases. For example, the well-documented problems of basal ganglia patients in initiating movement may be related to those cells with activity changes upon movement initiation. Parkinson's disease patients also suffer deficits in tasks requiring context-dependent switching of behavioral sets (Taylor et al., 1990). This can be manifcstcd as "poor use of navigational markers or contextual cues" (Sullivan et al., 1989). These navigational cues could be represented in the locationand heading direction-selective neurons. In rats, it is the lesions of the anterodorsal region that was studied here that have been shown to cause the most severe deficits in spatial performance tasks (Masuda and Iwasaki, 1984, and references within). Context dependent set switching could be associated with the cells active after rotations of the arena.

This ensemble of cell activity profiles represent to a surprisingly detailed degree a compartmentalization on a cellular level of many types of information that would be useful for navigation behaviors. For example, in one strategy to determine one's new position after a displacement in the dark (Mittelstaedt and Mittelstaedt, 1980, 1982; Etienne et al., 1990; Leonard and McNaughton, 1990), the neural coding of the initial position is incremented with the use of vestibular and kincsthetic signals that result from self-movements in a known direction over time. The present study shows that all of this information (location, movements, heading direction) is present in the striatum. These results support the view that the striatum plays a fundamental role in spatial navigation.

\section{References}

Alexander GE, Crutcher MD (1990a) Preparation for movement: neural representations of intended direction in three motor areas of the monkey. J Neurophysiol 64:133-150.

Alexander GE, Crutcher MD (1990b) Neural representations of the target (goal) of visually guided arm movements in three motor areas of the monkey. J Neurophysiol 64:164-178.

Apicella P, Scarnati E, Schultz W (1991) Tonically discharging neurons of monkey striatum respond to preparatory and rewarding stimuli. Exp Brain Res 84:672-675.

Bland BH (1986) The physiology and pharmacology of hippocampal formation theta rhythms. Prog Neurobiol 26:1-54.

Blum PS, Day MY, Carpenter MB, Gilman S (1979) Thalamic components of the ascending vestibular system. Exp Neurol 64:587-603.

Bowen FP, Kameny M, Burns M, Yahr MD (1976) Effects of levodopa on concept formation. Neurology 25:701-704.

Brodal A (1981) Neurological anatomy in relation to clinical medicine, 3d ed. Oxford: Oxford UP.

Chen LL, McNaughton BL, Barnes CA, Ortiz ER (1990) Head-directional and bchavioral corrclates of postcrior cingulate and medial prestriate cortex neurons in freely moving rats. Soc Neurosci Abstr $16: 441$.

Cook D, Kesner RP (1988) Caudate nucleus and memory for egocentric localization. Behav Neural Biol 49:332-343.

Crutcher MD, Delong MR (1984) Single cell studies of the primate putamen. II. Relations to direction of movement and pattern of muscular activity. Exp Brain Res 53:244-258.

Dubois B, Boller F, Pillon B, Agid Y (1991) Cognitive deficits in Parkinson's disease. In: Handbook of neuropsychology, Vol 5 (Boller F, Grafman J, eds), pp 195-240. Amsterdam: Elsevier.

Etienne A, Teroni E, Hurni C, Portenier V (1990) The effect of a single light cue on homing behavior of the golden hamster. Anim Behav $39: 17-41$.

Gardiner TW, Kitai ST (1992) Single-unit activity in the globus pallidus and neostriatum of the rat during performance of a trained head movement. Exp Brain Res 88:517-530.

Groenewegen HJ, Vermeulen-Van der Zee E, Te Kortschot A, Witter MP (1987) Organization of the projections form the subiculum to the ventral striatum of the rat: a study using anterograde transport of Phaseolus vulgaris leucoagglutinin. Neuroscience 23:103-120.

Hess BJM, Blanks RHI, Lannou J, Precht W (1989) Effects of kainic 
acid lesions of the nucleus reticularis tegmenti pontis on fast and slow phases of vestibulo-ocular and optokinetic reflexes in the pigmented rat. Exp Brain Res 74:63-80.

Hikosaka O, Sakamoto M, Usui S (1989a) Functional propertics of monkey caudate neurons. I. Activities relating to saccadic eye movements. J Neurophysiol 61:780-798.

Hikosaka O, Sakamoto M, Usui S (1989b) Functional properties of monkey caudate neurons. II. Visual and auditory responses. J Neurophysiol 61:799-813.

Hikosaka O, Sakamoto M, Usui S (1989c) Functional properties of monkey caudate neurons. III. Activities related to expectation of target and reward. J Neurophysiol 61:814-832.

Holm S (1979) A simple sequentially rejective multiple test procedure. Scand J Statist 6:65-70.

Jones EG, Leavitt RY (1974) Retrograde axonal transport and the demonstration of non specific projections to the cerebral cortex and striatum from thalamic intralaminar nuclei in the rat, cat and monkey. J Comp Neurol 154:349-378.

Kazdin AE (1984) Statistical analyses for single-case experimental designs. In: Single case experimental designs, 2d ed (Barlow DH, Herson M, eds), pp 285-324. New York: Pergamon.

Kelley AE, Domesick VB (1982) The distribution of the projection from the hippocampal formation to the nucleus accumbens of the rat an anterograde and retrograde horseradish peroxidase study. Neuroscience 7:615-630.

Kimura M (1990) Behaviorally contingent property of movementrelated activity of the primate putamen. J Neurophysiol 63:12771296.

Krauth J (1988) Distribution-free statistics: an application-oriented approach. Amsterdam: Elsevier.

Kubie JL, Muller RU, Bostock E (1990) Spatial firing properties of hippocampal theta cells. J Neurosci 10:1110-1123.

Kuypers HGJM, Kievit J, Groen-Klevant AC (1974) Retrograde axonal transport of HRP in rat's forebrain. Brain Res 29:363-365.

Leonard B, McNaughton BL (1990) Spatial representation in the rat: conceptual, behavioral and neurophysiological perspectives. In: Com parative cognition (Kesner RP, Olton DS, eds), pp 363-422. Hillsdale, NJ: Erlbaum.

Liedgren SRC, Milne AC, Rubin AM, Schwarz DWF, Tomlinson RD (1976) Representation of vestibular afferents in somatosensory thalamic nuclei of the squirrel monkey (Saimiri sciureus). J Neurophysiol 39:601-612.

Magnin M, Kennedy $\mathbf{H}$ (1979) Anatomical cvidence of a third ascending vestibular pathway involving the ventral lateral geniculate nucleus and the intralaminar nuclei. Brain Res 174:523-529.

Markus EJ, McNaughton BL, Barnes CA, Green JC, Meltzer J (1990) Head direction cells in the dorsal presubiculum integrate both visual and angular velocity information. Soc Neurosci Abstr 16:441.

Masuda Y, Iwasaki T (1984) Effects of caudate lesions on radial arm maze behavior in rats. Jpn Psychol Res 26:42-49.

Matthews BL, Ryu JH, Bockaneck C (1989) Vestibular contribution to spatial orientation. Acta Otolaryngol (Stockh) [Suppl] 468:149_ 154.

McGeorge AJ, Faull RLM (1989) The organization of the projection from the cerebral cortex to the striatum in the rat. Neuroscience 29 : 503-538.

McNaughton BL, Barnes CA, O'Keefe J (1983) The contributions of position, direction, and velocity to single unit activity in the hippocampus of freely-moving rats. Exp Brain Res 52:41-49.

Miller R (1991) Cortico-hippocampal interplay and the representation of contexts in the brain. Berlin: Springer.

Mitchell SJ, Richardson RT, Baker FH, DeLong MR (1987) The primate globus pallidus: neuronal activity related to direction of movement. Exp Brain Res 68:491-505.

Mittelstaedt H, Mittelstaedt M-L (1973) Mechanismen der Orientierung ohne richtende Aussenreize. Fortschr. Zool. 21, Heft 2/3. Stuttgart: Fischer.

Mittelstaedt H, Mittelstaedt M-L (1982) Homing by path integration. In: Avian navigation (Papi H, Wallraff G, eds), pp 290-297. Heidelberg: Springer.

Mittelstaedt M-L, Glasauer S (1991) Idiothetic navigation in gerbils and humans. Zool Jahrb Physiol 95:427-435.

Mittelstaedt M-L, Mittelstaedt H (1980) Homing by path integration in a mammal. Naturwissenschaften 67:566.

Mizumori SJY, Williams JD (1991) Mnemonic properties of visual- sensitive head direction cells in lateral dorsal thalamus. Soc Neurosci Abstr 17:482.

Muller RU, Kubie JL, Ranck JB Jr (1987a) Spatial firing patterns of hippocampal complex-spike cells in a fixed environment. J Neurosci 7:1935-1950.

Muller RU, Kubie JL, Ranck JB Jr (1987b) The effects of changes in the environment on the spatial firing of hippocampal complex-spike cells. J Neurosci 7:1951-1968.

Nauta WJH, Pritz MB, Lasek RJ (1974) Afferents to the rat caudatoputamen studied with HRP. An evaluation of a retrograde neuroanatomical research method. Brain Res 67:219-238.

O'Keefe J, Conway DH (1978) Hippocampal place units in the freely moving rat: why they fire where they fire. Exp Brain Res 31:573-590.

O'Keefe J, Speakman A (1987) Single unit activity in the rat hippocampus during a spatial memory task. Exp Brain Res 68:1-27.

Olton D, Samuelson RJ (1976) Remembrance of places past: spatial memory in rats. J Exp Psychol 2:97-1 16.

Packard MG, Hirsh R, White NM (1989) Differential effects of fornix and caudate nucleus lesions on two radial maze tasks: evidence for multiple memory systems. J Neurosci 9:1465-1472.

Paxinos $G$, Watson $C$ (1986) The rat brain in stereotaxic coordinates, 2d ed. Sydney: Academic.

Potegal M (1969) Role of the caudate nucleus in spatial orientation of rats. J Comp Physiol Psychol 69:756-764.

Potegal M (1971) A note on spatial-motor deficits in patients with Huntington's disease: a test of a hypothesis. Neuropsychologia 9:233235.

Potegal M, Copack P, deJong JM, Krauthamer G, Gilman S (1971) Vestibular input to the caudate nucleus. Exp Neurol 32:448-465.

Quirk GO, Muller RU, Kubie JL (1990) The firing of hippocampal place cells in the dark depends on the rat's recent experience. J Neurosci 10:2008-2017.

Quirk GO, Muller RU, Kubie JL, Ranck JB Jr (1992) The positional firing properties of medial entorhinal neurons: description and comparison with hippocampal place cells. J Neurosci 12:1945-1963.

Rolls ET, Johnstone S (1992) Neurophysiological analysis of striatal function. In: Neuropsychological disorders associated with subcortical lesions (Vallar G, Cappa SF, Wallesch CW, eds), pp 61-97. Oxford: Oxford UP.

Rolls FT, O'Mara SM (1993) Neurophysiological and theoretical analysis of how the hippocampus functions in memory. In: Brain mechanisms of perception: from neuron to behavior (Ono T, Squire L, Raichle M, Perrett D, Fukudo M, eds). New York: Oxford UP.

Schultz W (1989) Neurophysiology of the basal ganglia. In: Handbook of experimental pharmacology, Vol 88 (Caine DB, ed), pp 1-45. Berlin: Springer.

Schultz W, Romo R (1988) Neuronal activity in the monkey striatum during the initiation of movements. Exp Brain Res 71:431-436.

Speakman A, O'Keefe J (1990) Hippocampal complex spike cells do not change their place fields if the goal is moved within a cue controlled environment. Eur J Neurosci 2:544-555.

Steele RGD, Torrie JH (1960) Principles and procedures of statistics with special reference to the biological sciences. New York: McGrawHill.

Sullivan EV, Sagar HJ, Gabrieli JDE, Corkin S, Growdon JH (1989) Different cognitive profiles on standard behavioural tests in Parkinson's disease and Alzheimer's disease. J Clin Exp Neuropsychol 11: 799-820.

Swanson LW, Cowan WM (1977) An autoradiographic study of the organisation of the efferent connections of the hippocampal formation in the rat. J Comp Neurol 172:49-84.

Swanson LW, Köhler C (1986) Anatomical evidence for direct projections from the entorhinal area to the entire cortical mantle of the rat. J Neurosci 6:3010-3032.

Taube JS, Muller RIJ, Ranck JB Jr (1990a) Head-direction cells recorded from the postsubiculum in freely moving rats. I. Description and quantitative analysis. $J$ Neurosci 10:420-435.

Taube JS, Muller RU, Ranck JB Jr (1990b) Head-direction cells recorded from the postsubiculum in freely moving rats. II. Effects of environmental manipulations. J Neurosci 10:436-447.

Taylor AE, Saint-Cyг JA, Lang AE (1990) Subcognitive processing in the frontocaudate "complex loop": the role of the striatum. Alzheimer Dis Assoc Disord 4:150-160.

Teuber HL (1976) Complex functions of the basal ganglia. In: The basal ganglia (Yahr MD, ed), pp 151-168. New York: Raven. 
Veening JG, Cornelissen FM, Lieven PAJM (1980) The topical organization of the afferents to the caudatoputamen of the rat. A horseradish peroxidase study. Neuroscience 5:1253-1268.

Whishaw IQ, Mittleman G, Bunch ST, Dunnett SB (1987) Impairments in the acquisition, retention and selection of navigation strategies after medial caudate-putamen lesions in rats. Behav Brain Res 24:125-138.

Wiener SI, Paul CA, Eichenbaum H (1989) Spatial and behavioral correlates of hippocampal neuronal activity. J Neurosci 9:2737-2763.
Wilson C (1991) The basal ganglia. In: Synaptic organization of the brain (Shepherd G, ed), pp 279-316. Oxford: Oxford UP.

Wilson C, Groves PM (1981) Spontaneous firing patterns of identified spiny neurons in the rat neostriatum. Brain Res 220:67-80.

Winer BJ (1971) Statistical principles in experimental design, 2d ed. New York: McGraw-Hill 